\title{
Investigating the Labor and Capital Contributions and their Effective Factors in Iran
}

\author{
Yadollah Dadgar ${ }^{1}$ \\ Simin Taheri ${ }^{2}$ \\ Hassan $\mathrm{Taee}^{3}$
}

\author{
| Y_Dadgar@sbu.ac.ir \\ sim.taheri@sbu.ac.ir \\ taee@atu.ac.ir
}

\begin{abstract}
One of the main issues in economy is the extent of labor and capital contributions in production of goods and services; since the contribution of production factors is a main step in economic planning and policy making that aim to reduce the class gap and income inequality. This study, following Piketty approach, investigates the labor and capital contributions for Iran's economy during 1985-2014. In calculating the share of such factors, oil-based and non-oil-based GDP were taken into account. To achieve this objective, the effective factors on labor and capital contribution have been estimated using Auto-Regressive Distributed Lag (ARDL). The results indicate a direct relationship between minimum wage and labor productivity indices, and negative relationship of inflation rate, unemployment rate and profit margin of exchange rate with labor contribution in national income. Moreover, the results indicate a direct relationship between capital inventory and rate of return, and a negative correlation between inflation, capital price and gross domestic product with capital contribution in national income. The sign of oil-free model coefficients, except for the unemployment rate coefficient, are similar to those of the oil-based labor share model. Factors influencing the share of capital in national income are similar to those factors that affect the share of labor in income, despite the fact that the sign of the coefficients is different.
\end{abstract}

Keywords: Piketty, Contribution of Labor Factor, Contribution of Capital Factor, Auto-Regressive Distributed Lag (ARDL) Pattern, Rate of Return on Capital.

JEL Classification: D33, D24, C89, C13.

\footnotetext{
1. Professor, Faculty of Economic and Political Sciences, Shahid Beheshti University, Tehran, Iran. 2. M.A. Student of Economics, Shahid Beheshti University, Tehran, Iran (Corresponding Author).

3. Associate Professor, Faculty of Economics, University of Allameh Tabatabai, Tehran, Iran.
} 


\section{بررسى سمهربرى كار و سرمايه و عوامل موثر بر آنها در ايران \\ Y_Dadgar@sbu.ac.ir \\ يدالله دادكر}

استاد دانشكده علوم اقتصادى و سياسى، دانشكاه شهيد بهشتى، تهران،

(نويسندهمسئول).

sim.taheri@sbu.ac.ir

سيمين طاهرى

دانشجوى كارشناسى ارشد علوم اقتصادى، دانشعاه شهيد بهشتى، تهران.

taee@atu.ac.ir

حسن طائى دانشيار دانشكده اقتصاد دانشعاه علامه طباطبايى، تهران. مقاله يزووهشى

دريافت: سו/9-/א"

ج جكيده: يكى از مسائل برجسته در اقتصاد، ميزان سهممبرى عوامل كار و سرمايه در جريان

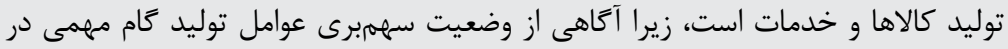

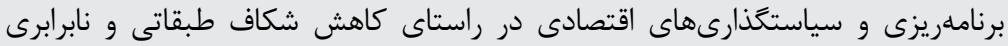

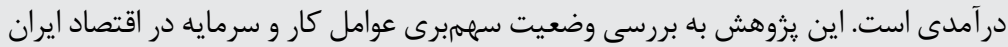

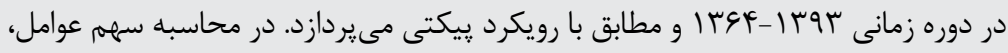

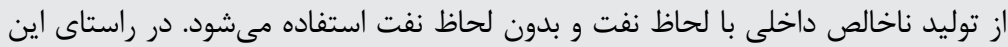

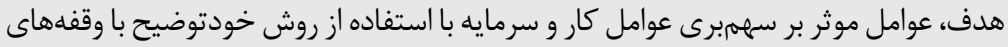

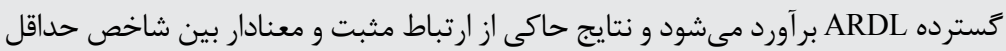

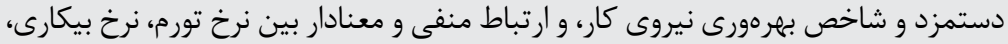

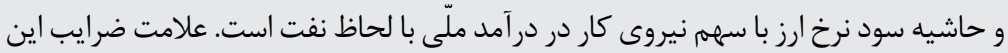

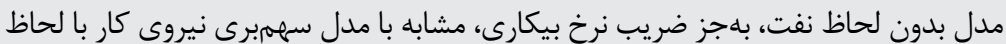

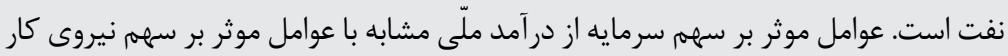

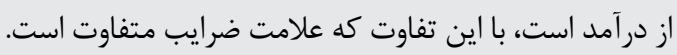

كليدوازهها: پيكتى، سهمبرى عامل كار، سهمبرى عامل سرمايه، الگوى خودتوضيح با

$$
\text { وقفههاى گسترده، نرخ بازدهى سرمايه. }
$$

طبقهبندى D33, D24, C89, C13 :JEL. 
سهمبرى عوامل توليد از درآمد ملّى، يكى از اجزاى اصلى نظام توزيع درآمد و ثروت است كه كه

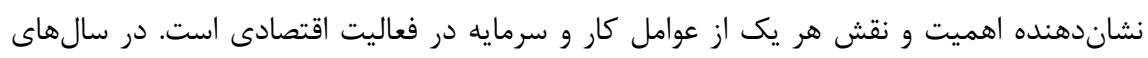
اخير به دليل شواهد بسيار در مورد نوسانها و بـثباتى سهمم عوامل كار و سرمايه در توليد، موضوع

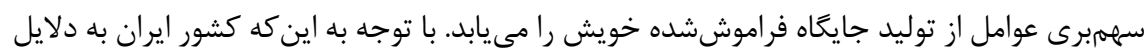

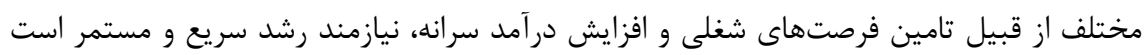

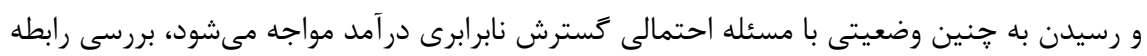

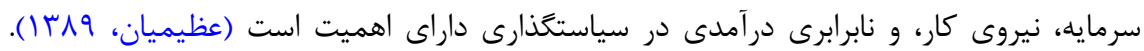

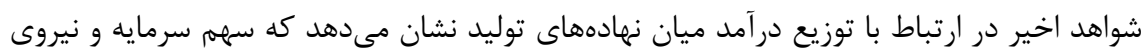

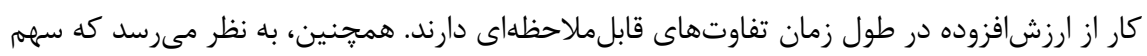
نيروى كار در سراسر جهان در حال كاهش است (Guerriero \& Sen, 2012). در واقع، نيروى كار

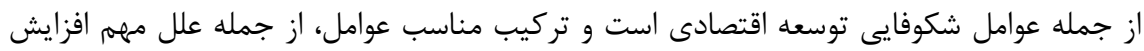

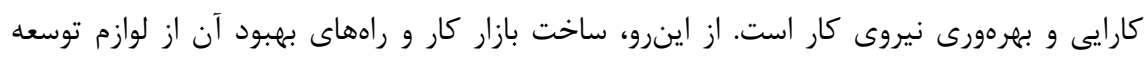
است. توزيع درآمد به شيوه مناسب و مزد منصفانه نيز با كاهش نابرابرى از بروز تضادهاى اجتماعى برى باري

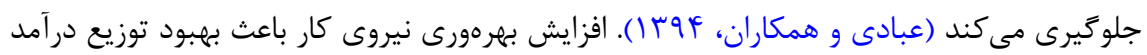

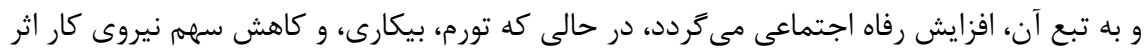

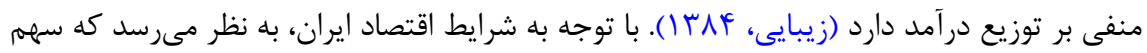

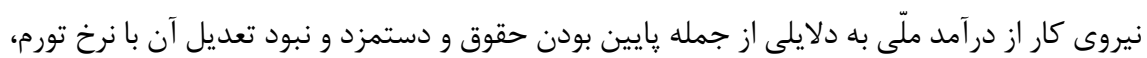

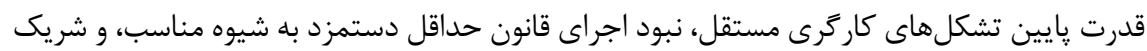

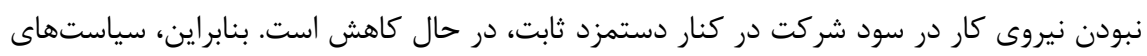

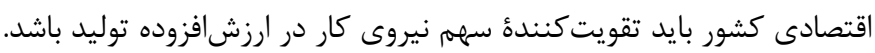

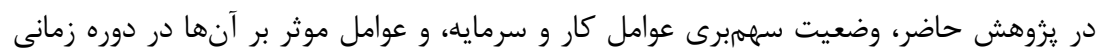

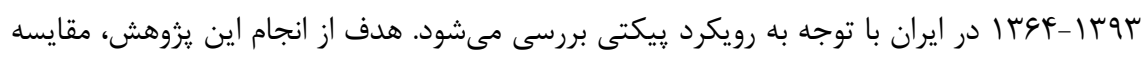

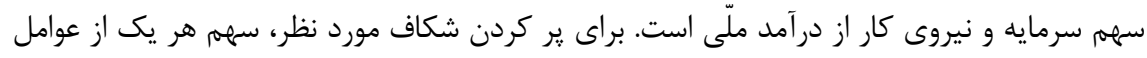

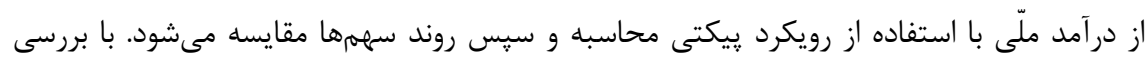

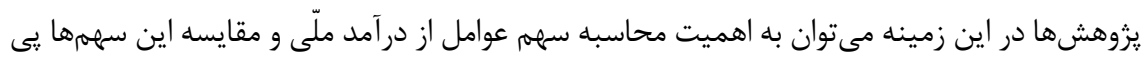




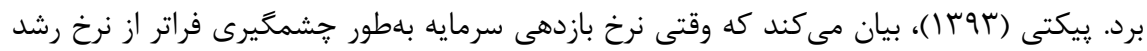

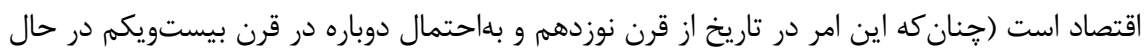

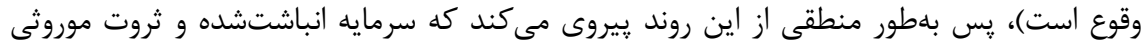

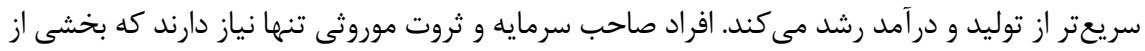

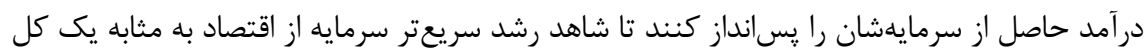

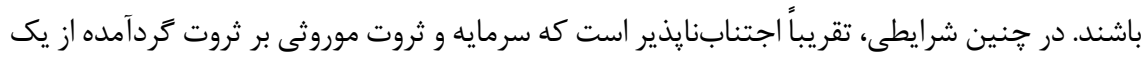

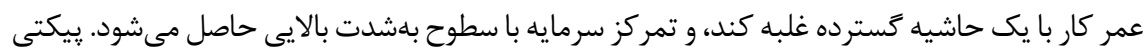

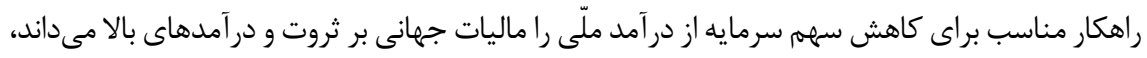

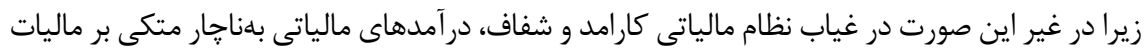

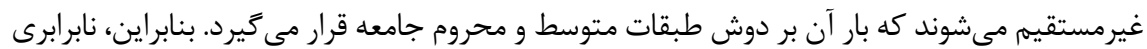

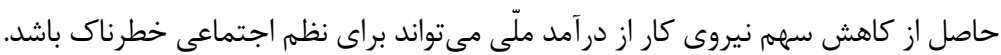

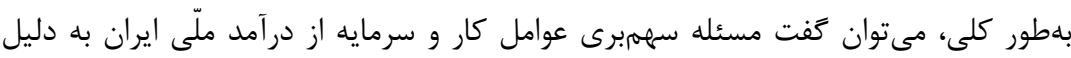

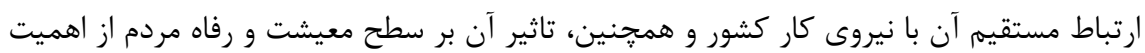

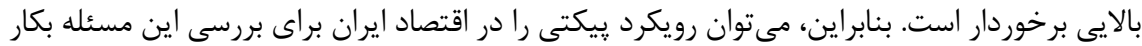

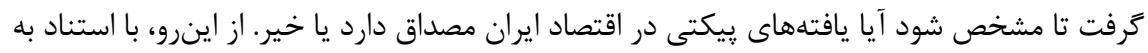

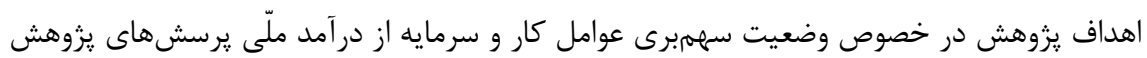

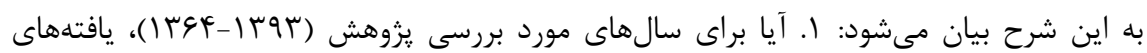

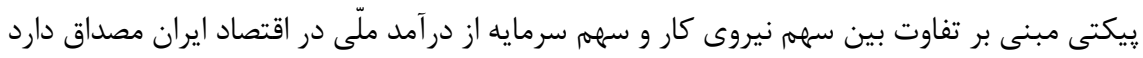

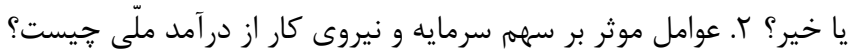

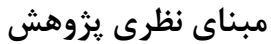

\section{رويكرد بيكتى}

مطابق با رويكرد يُيكتى، سهمه نيروى كار و سرمايه به اين صورت بهددست مى آيد: ابتدا با استفاده

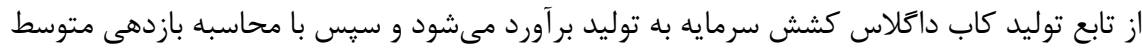

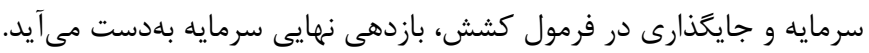


$\mathrm{e}=\mathrm{MP}_{\mathrm{K}} / \mathrm{AP}_{\mathrm{K}}$

$\mathrm{AP}_{\mathrm{K}}=\mathrm{Q} / \mathrm{K}$

$\mathrm{MP}_{\mathrm{K}}=\mathrm{r}$

در رابطه (Y)، e كشش سرمايه به توليد، AP بازدهى متوسط سرمايه، و MP بازدهى نهايى سرمايه است.

$\beta=\mathrm{K} / \mathrm{Y}$

در رابطه (ب)، م برابر با نسبت سرمايه به در آمد است.

$\alpha=r \times \beta$

$\mathrm{KS}=\alpha$

در رابطه (1)، سهمم سرمايه از درآمد ملّى برابر با نرخ بازدهى نهايى سرمايه در نسبت سرمايه به

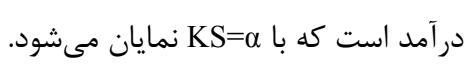

$\mathrm{LS}=1-\alpha$

(ఎ)

سهم نيروى كار از درآمد ملّى برابر با ه-1 است كه با LS مشخص است.

شرح كوتاهى بر انديشههاى اقتصاددانان ييشين در ارتباط با سهمبرى عوامل توليد در ادامه به شكلى كذرا شرح تاريخي مختصرى از تفكرها و انديشههاى پيشين مرتبط با اين موضوع ارائه مىشود. مالتوس'

نظرهاى مالتوس در باب سازوكار فقر و نابر ابرى را مى توان به اين ترتيب خلاصه كرد كه دستمزد يولى و

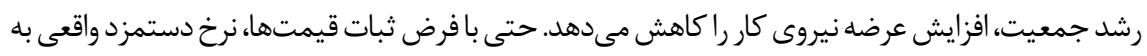

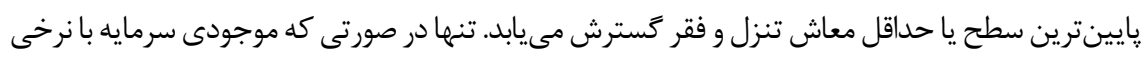

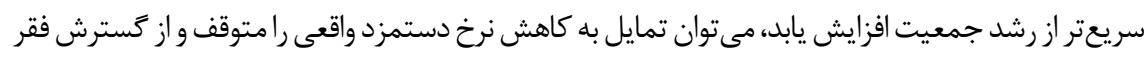

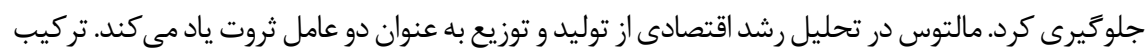

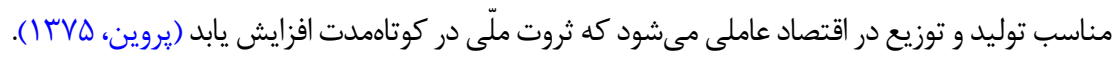




\section{ريكاردو'}

ريكاردو و ماركس` معتقدند كه يك گروه كوجى اجتماعى - زمينداران از نظر ريكاردو، و

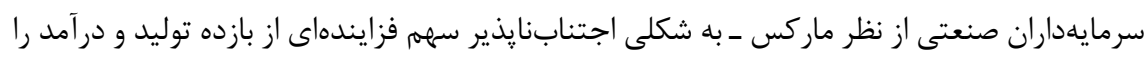
به خود اختصاص مىدهند. ريكاردو به اين تناقض منطقى اشاره مى كند: هنگامى كه جمعيت و بازده آنس

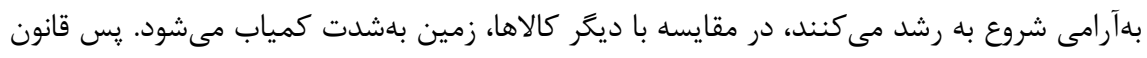

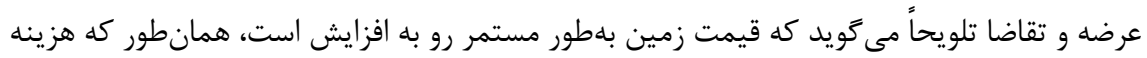

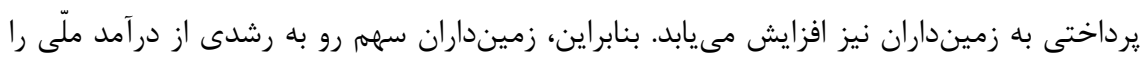

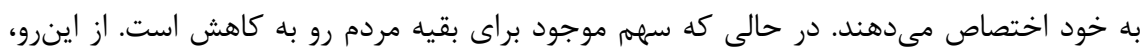

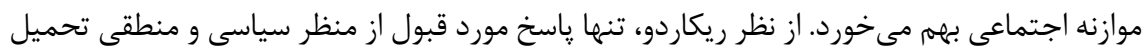

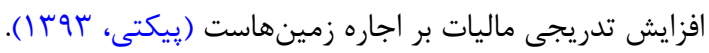

\section{ماركس}

ماركس بهجاى اينكه مانند ريكاردو روى املاك و زمين تمركز كند، سرمايه را مبناى تحليل خود قرار داد، جرا كه در آن زمان هيج محدوديتى براى ميزان سرمايهاى (ماشين آلات و كارخانهانها)

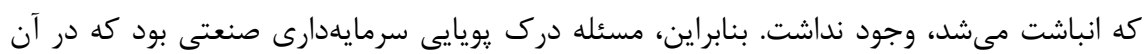

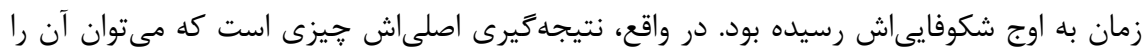

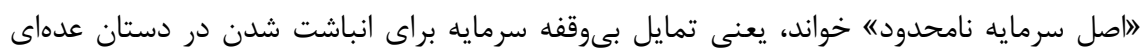

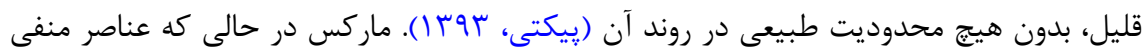

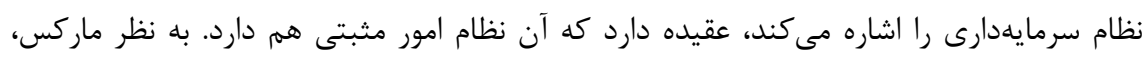

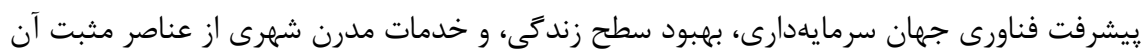

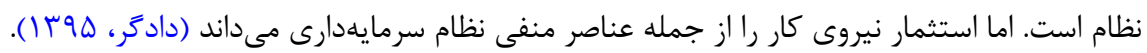

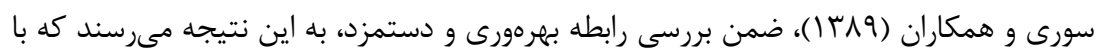

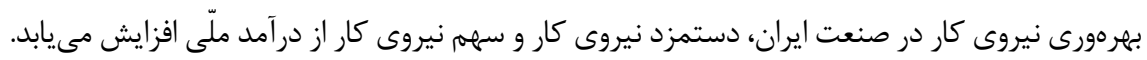

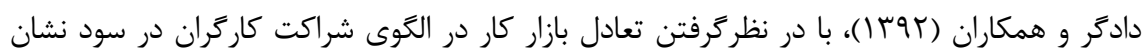

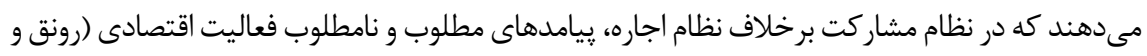
ركود اقتصادى) متوجه هر دو طرف قرارداد، يعنى نيروى كار و صاحب سرمايه است و نتايج حاصل از آن 


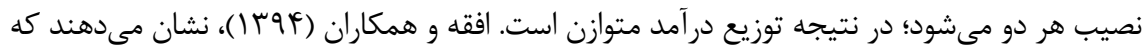
سهمم نيروى كار در تمامى زيربخشها بسيار كمتر از سهم سرمايه است. طائى و همكاران (هوس (1)، بيان

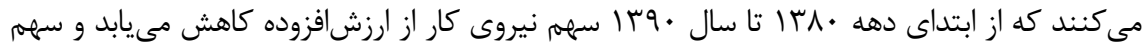

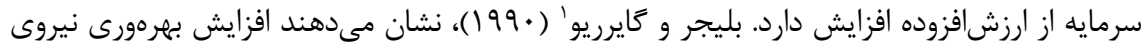
كار (براى مثال از راه دستمزد)، افزايش نرخ حقيقى ارز، و نرخ حقيقى بهره به كاهش نابرابرى بين سهرئم

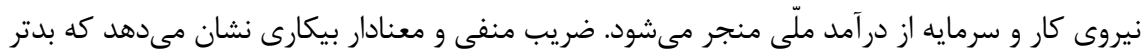

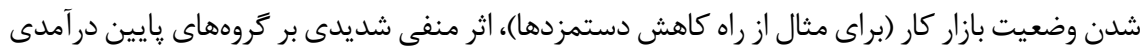

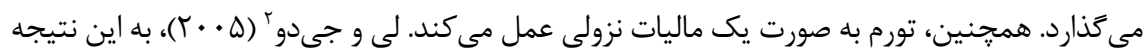

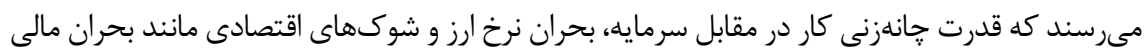
روى سهم كار از درآمد نقش دارد. براى مثال درجه باز بودن مالى، انتقال سرمايه به مكان توليد را آسانتر مى كند و در نتيجه، قدرت جانهزنى سرمايه را در مقابل كار افزايش مى دهدد. در مقابل كنترل سرمايه،

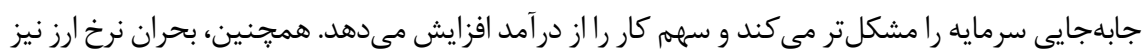

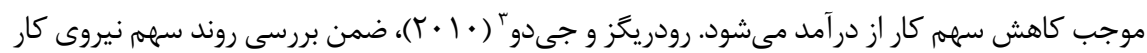

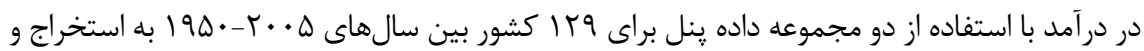

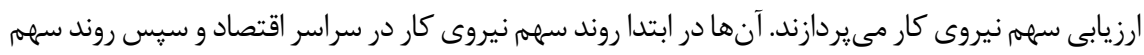

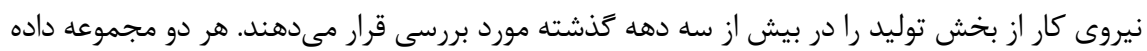
نشان مى دهد كه از حدود سال • •19 1، در بسيارى از مناطق جهان سهرم نيروى كار كاهش دارد. كوئريرو

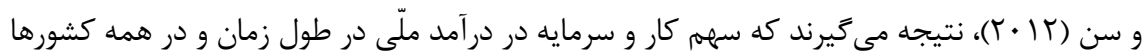

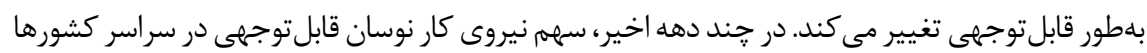

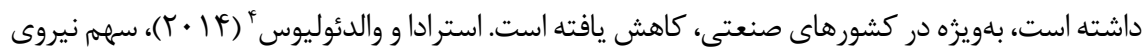
كار را به عنوان يك عامل تعيين كننده كليدى از متغيرهاى كلان اقتصادى معرفى مى كنند. همجنين،

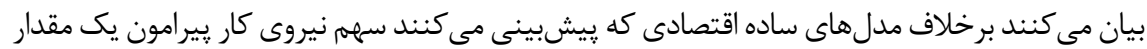
بلندمدت نوسان مى كند، در سه دهه كذشته اين متغير يك روند نزولى از خود به نمايش ميى خذارد.

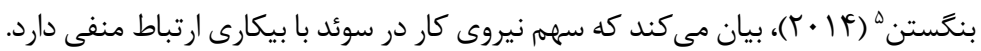

1. Blejer \& Guerrero

2. Lee \& Jayadev

3. Rodriguez \& Jayadev

4. Estrada \& Valdeolivas

5. Bengtsson 


\section{روششناسى يزوهش}

در اين يزوهش از روش توصيفى ـ تحليلى و تلفيقى وضعيت سهممبرى كار و سرمايه در دوره

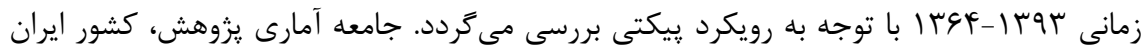
و روش گردآورى اطلاعات كتابخانهاى است. آمار و اطلاعات براى سرى زمانى از بانكى اطلاعات سرىهاى زمانى اقتصادى - بانك مركزى'، سالنامههاى آمارى و درگًه ملّى آمارَّ، بانك جهانى

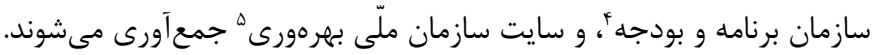

\section{تجزيلوتحليل و تصريح مدل}

در اين يزوهش، تغييرهاى سهم نيروى كار و سرمايه در ايران به دليل اهميت مسئله تاثير اين

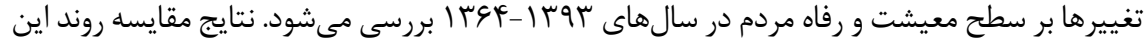

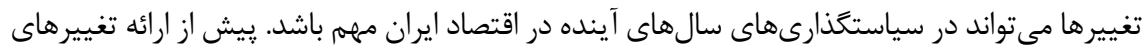
سهم نيروى كار و سرمايه از در آمد ملّى لازم است روش محاسبه سهم اين عوامل ارائه شود. روش محاسبه

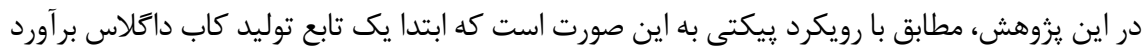
مىشود و كشش توليدى سرمايه بهدست مى آيد. سيس با محاسبه بازده متوسط سرمايه (AP جايگذارى در فرمول كشش توليدى سرمايه به صورت C=MP مىشود. جايگذارى بازده نهايى سرمايه (r= MP)، در اولين قانون بنيادى سرمايهدارى ارائهشده توسط

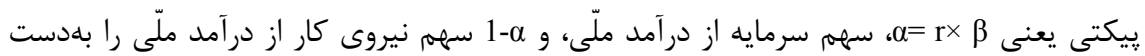

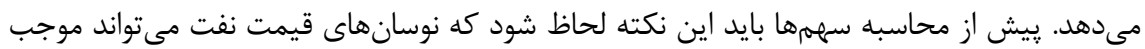

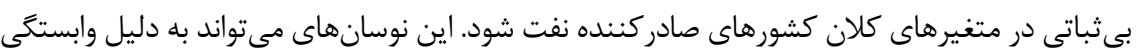

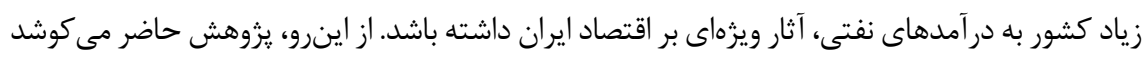

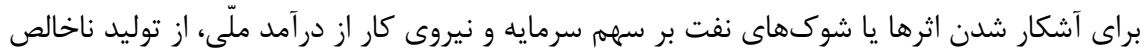
داخلى بدون نفت و با لحاظ نفت در محاسبه سهمها استفاده كند. نتايج محاسبه سهمم اين عوامل و

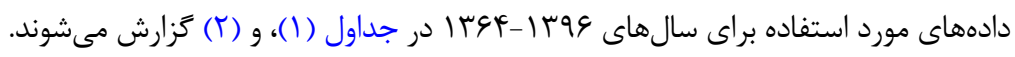

1. www.cbi.ir

2. www.amar.org.ir

3. www.worldbank.org

$9 \quad$ 4. www.mporg.ir

5. www.npo.gov.ir 


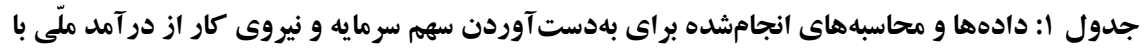

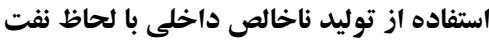

\begin{tabular}{|c|c|c|c|c|c|c|c|}
\hline 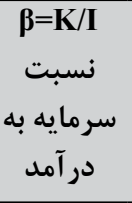 & در آمد ملّى & $\begin{array}{c}\text { MP } \mathbf{P}_{\mathbf{k}}=\mathbf{r}=\mathbf{e} \cdot \mathbf{A P} \mathbf{P}_{\mathbf{K}} \\
\text { سازده نهايبى }\end{array}$ & 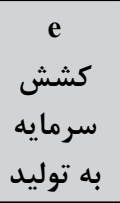 & 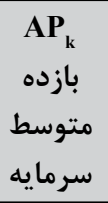 & 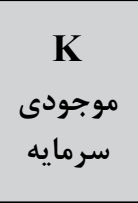 & 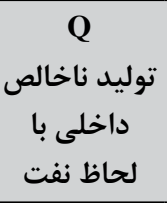 & سال \\
\hline$\Delta / \cdots r q \mid$ & VIIT⿰V & $\cdot / 1 \cdot V 9$ & $\cdot / f F$ & - ITFFA & $r \Delta \Delta ৭ \Delta, \wedge$ & $\Lambda V \cdot r \Delta l$ & IrGF \\
\hline$\varepsilon / 4 \& 9 \Delta F$ & $\Delta F \Delta V \cdot 1$ & $.1 .9 \vee 9$ & 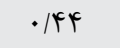 & - ITTYF & $r \Delta r \cdot q r \Delta$ & VADY৭D & Dad \\
\hline$\Delta / 19 \wedge 94$ & GNDGYG & .1 .971 & $\cdot \mid k f$ & $\cdot / T T \cdot \Lambda$ & TAGYATr & VASqTY & IrG4 \\
\hline 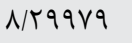 & FTVTME & $.1 .9 T \Delta$ & $\cdot / f F$ & $\cdot|r| \cdot r$ & $r \Delta F \Delta ৭ ૬ \wedge$ & VFATAV & IrGV \\
\hline$V / F \mid Y \Delta I$ & $r \wedge F \cdot \Delta$. & .1 .941 &.$/ f F$ &.$/ 4199$ & $r \Delta \wedge \wedge \Delta \cdot q$ & VА१וr & IrgA \\
\hline$\varepsilon / \cdot \Delta \Delta \wedge F$ & $\Delta \wedge १ \curlyvee \Delta \Lambda$ &.$/ 111$. & 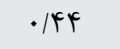 & - ITAYT & 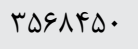 & ^৭৭৭४১ & 1 1raq \\
\hline D/AYArA & GTNFTV & .11190 & 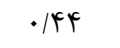 & . ITVIS & TVT.99T & $1 \cdot 1 \cdot 9 \cdot 1$ & Irv. \\
\hline D/qIVTA & $9 \Delta|f|$. & .11119 & $\cdot / F F$ & $\cdot / r V \cdot r$ & rADFDVD & $1 \cdot F \mid \Delta V$. & $|r v|$ \\
\hline$F / F \Delta \cdot F r$ & 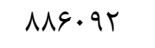 & $\cdot / 11 \mathrm{VA}$ & $\cdot / F F$ & . /TEV & rqFrFAV & $1 \cdot \Delta \Delta \& q$. & ITV \\
\hline$F / \Delta \Delta \Delta G \wedge$ & $\wedge \vee \wedge / 99$ & $\cdot / 110$. & - IFF & $\cdot|r \&| F$ & $p \cdots v q 1$ & $1 \cdot f \Delta q g r$ & IrV \\
\hline F/VTGDI & $\Lambda \Delta \Delta \Delta G G$ & .11199 & $\cdot / F F$ & . /TSDS & F. FrNAT & $1 \cdot V F \cdot F F$ & IrVF \\
\hline$F / \Delta 9 \wedge \Lambda$. & $q \cdots \mid \Delta r$ & r & $\cdot / F F$ & . ITVKF & FIragr। & 1111949 & $1 \pi v \Delta$ \\
\hline F/9YGVA & AETYAF & $\cdot / 1111$ & $\cdot / F F$ & - /rGAr & FTATTIT & $\|f\| r \cdot \Delta$ & IrVG \\
\hline$\Delta / \varepsilon \cdot r \Delta \Delta$ & $\vee \vee १ \backslash \wedge \Delta$ & $\cdot / 11 \vee \Delta$ & $\cdot / F F$ & $\cdot|r \& V|$ & frsq911 & llGGTVG & IrV \\
\hline$F / \wedge \Delta \vee G$. & GTFTD. &.$/ 1195$ & $\cdot / f F$ & - ITEFT & FFへ৭૬TD & I1^बIVV & IrVA \\
\hline F/AFG|G & $9 \Delta \Delta \Delta T K$ & .11191 & $\cdot / F F$ & $\cdot / T V \cdot V$ & fGr.G. 9 & ITAKFV & $1 \pi v 9$ \\
\hline f/Aqfrq & १८१६४ &.$/ 1195$ & $\cdot / F F$ &.$|r g 4|$ & FAFrGGA & |rVq।qr & $1 r \Lambda$. \\
\hline F/MGYGD & $1194 \cdot r 9$ & .11199 & $\cdot / F F$ & - ITVYG & $\Delta \cdot V \curlyvee \wedge \wedge \Lambda$ & |r人सा|द & $|r \Lambda|$ \\
\hline F/TVGIV & ITFYA. & . IIYFI & $\cdot / F F$ & $\cdot / r 119$ & $\Delta K I \Lambda V \cdot q$ & 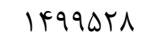 & IrNT \\
\hline 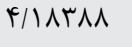 & IMTKFTD & • IITHV & $\cdot / F F$ & $\cdot|r \Lambda| \cdot$ & $\Delta \Delta \Lambda r \cdot V \Lambda$ & 1099.99 & IrNK \\
\hline r/ANFrI & $1 \Delta \cdot \vee r \Delta q / \Lambda$ & - /ITAF & $\cdot / F F$ & $\cdot / r \wedge \& q$ & $\Delta \wedge \Delta \Delta \cdot \Delta \Lambda$ & $199 \wedge 1 \wedge 9 / 1$ & IrNF \\
\hline r/AITUT & $19 . . r F F / \Lambda$ & - ITVE & $\cdot / f F$ & $\cdot / 1 \wedge 99$ & $G 1 \cdot r q Y Q$ & IVGqFYG & $1 r \wedge \Delta$ \\
\hline$\Gamma / \Delta \gamma \cdot \varphi \Delta$ & IV^৭৭^४/D & & $\cdot / F F$ & . & grq|f|f & $19.9448 / V$ & Ir人s \\
\hline r/VArFI & $I V \vee \wedge I V V / A^{c}$ & - / TLD & $\cdot / F F$ & - /rNAL & SVTVDVA & $191 \wedge 9 \wedge 1$ & IrAV \\
\hline F/lFEIT & $\mid V \cdot F \Delta \Phi \Delta / 1$ & $.|| r \mid$. & $\cdot / F F$ & . IrVFq & V.GVTRG & $19 F r 919 / \Delta$ & IrAN \\
\hline
\end{tabular}


ادامه جدول ا: دادهها و محاسبههاى انجامشده براى بهدست آوردن سهم سر مايه و نيروى كار از درآمد

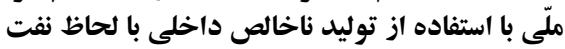

\begin{tabular}{|c|c|c|c|c|c|c|c|}
\hline 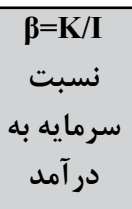 & در آمد ملّى & $\begin{array}{c}\text { MP } P_{k}=r=e \cdot A P_{K} \\
\text { بازده نهاييى }\end{array}$ & كشش سبش & 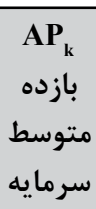 & $\begin{array}{c}\text { K } \\
\text { موجودى مايه }\end{array}$ & $\begin{array}{c}\text { Q } \\
\text { داخليد ناخالص باظ نفا } \\
\text { داخلى }\end{array}$ & سال \\
\hline T/QGTrG & $|\Lambda V| \& T V / \&$ & . ITTV & $\cdot \mid F F$ & $\cdot / r \vee q$. & $V F|g| \cdot G$ & $r \cdot 9 \wedge 91 / 9$ & $14 \wedge 9$ \\
\hline$r / q \cdot r \cdot r$ & $199 \cdot r 81 / r$ & . ITYT & $\cdot \mid F F$ & $\cdot / T V V V$ & $v \nabla v \cdots r \Delta$ & rIDVqrF/l & וrq. \\
\hline 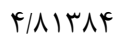 & IEYAYFA/I & .11110 & $\cdot \mid F F$ & - / TUMF & Vqrar।9 & $r \cdot \| \Delta \Delta \Delta r$ & $\mid r q 1$ \\
\hline$\Delta / \cdot \mid \Delta r \Lambda$ & 19.9419 & $\cdot / 1 \cdot V V$ & $\cdot \mid F F$ & - IFFFq & $\Lambda \cdot \Delta \& r \wedge q$ & I QVTADT & IrqT \\
\hline ১/IV৭G. & $\mid \Delta \Lambda \cdot r F \Lambda$ & $.11 \cdot 94$ & $\cdot \mid k F$ & - ITFAT & $\wedge 1 \wedge \Delta \Delta \& \varphi$ & $r \cdot r \mid \Delta ৭ \varphi$ & \\
\hline G/FIFVF & IFTYTIT/T & $.1 .9 \Leftrightarrow 4$ & $\cdot \mid F F$ & $\cdot|r| 9 \mid$ & 9I TrVGV & ।৭9१४६//।६ & $1 r q 4$ \\
\hline G/FAGIT & IDGFDFF/DT & $.1 .9 \vee \Delta$ & $\cdot / F F$ & . TKIV & 1.1 FVA19 & TYFQSDG/NF & 1490 \\
\hline G|VEq9I & $19 V K \cdot G T / G K$ & .1 .9 .9 & $\cdot \mid F F$ & $\cdot 1 \pi \cdot 94$ & IITqFVDV & F & Irq9 \\
\hline
\end{tabular}

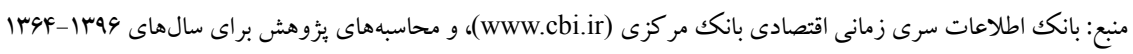

جدول r: سهم سرمايه و نيروى كار از در آمد ملّى با استفاده از توليد ناخالص داخلى با لحاظ نفت براى

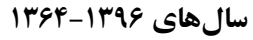

\begin{tabular}{|c|c|c|}
\hline Lيهم نيروى كار از در آمد ملّىى & ks:سهمم سر مايه از در آمد ملّى & سال \\
\hline 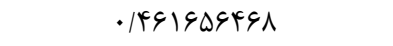 & - IOTNKFTATt & IrGF \\
\hline - rG\&AIFVqF & . |GKTINDT. & 1490 \\
\hline ./4q4qqसTGF & $\cdot 10 \cdot \Delta \cdot \cdot 99 T_{9}$ & 1 Heg \\
\hline •/TMTRVYAqY & -IVGVGTDI.G & IHEV \\
\hline$\cdot / r \Lambda T G \Lambda \cdot F G V$ & • & IrGA \\
\hline 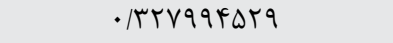 & $\cdot|G V T \cdot \Delta F V|$ & 1489 \\
\hline •/r. r४qqq४q & $\cdot 1999 \Delta \cdots \Delta F$ & IrV. \\
\hline 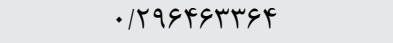 & •/V• rDHGGHG & $|r V|$ \\
\hline$\cdot / F \vee \Delta V \wedge F+F$ & - |QTFYID१৭Q & ITVT \\
\hline 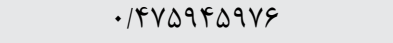 & $\cdot \mid \Delta T F \cdot \Delta F \cdot T r$ & IrVT \\
\hline - IFAVGAITAV & - /DQTHOAVFF & ITVE \\
\hline - KFEGAVGTF & •IDQRT. KRVG & ITVD \\
\hline
\end{tabular}


ادامه جدول r: سهم سرمايه و نيروى كار از در آمد ملّى با استفاده از توليد ناخالص داخلى با لحاظ نفت

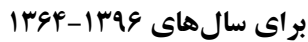

\begin{tabular}{|c|c|c|}
\hline سهرم نيروى كار از در آمد ملّى:Ls & ks:سهمم سرمايه از در آمد ملّى & 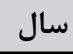 \\
\hline$\cdot / 4) \wedge r q \vee \wedge \cdot r$ & $\cdot|0 \Lambda| V \cdot r \mid 9 \Lambda$ & ITVG \\
\hline$\cdot\left|K^{\prime}\right| r \Delta s \mid \cdot q$ & 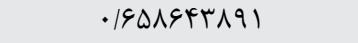 & IrV \\
\hline 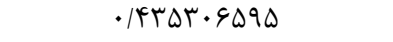 & - IDSYGqRT. D & IrVA \\
\hline •/FTrVq৭タ.1 & ./DVVT..rqq & Irvq \\
\hline . IFTIKEITF & - IDGAVYAVG & וrی. \\
\hline - IFVGVTGIFT & • IOTRTERADV & $|r \wedge|$ \\
\hline 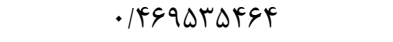 & - IOH. FEFDHG & IrNT \\
\hline - IFATEKINID & - $|\Delta| V K G \wedge \mid \wedge \Delta$ & Ir人ץ \\
\hline$\cdot|\Delta| r \cdot \Delta F G Y F$ & - /Fへ૬qFarVG & IrNF \\
\hline •|DITDITGAN & - RAGFAVTIT & Irیa \\
\hline •|DKITVTIVT & - KGEAGTVATA & Irیs \\
\hline • DQTATHKIVF & - IFVFVGGATE & ITAV \\
\hline - IFqAFDQFFF & $\cdot 10 \cdot 1 \Delta F F \Delta V G$ & Ir人 \\
\hline |DITETMITI & 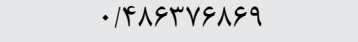 & 1 1 $\wedge 9$ \\
\hline - |DTtarifAF & $\cdot|F \vee V \cdot q \wedge \Delta| \varepsilon$ & $1 \% 9$. \\
\hline 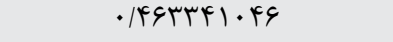 & 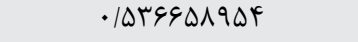 & $\mid r q 1$ \\
\hline - / $4 \Delta 9 \Delta 9 \wedge \& \Delta q$ & $\cdot|\Delta q \cdot r \cdot| r q \mid$ & 1495 \\
\hline - IFTFMETEVT & • IDGDGKGTYA & 1rar \\
\hline$\cdot|r \wedge| F \wedge \Delta \cdot \psi \mid$ & - $|9| \wedge \Delta \mid \& 9 \Delta 9$ & 1494 \\
\hline - MGVTYFFAD & - |GTYGVDDID & 1149 \\
\hline - /KAGGYGAGK & - & 1499 \\
\hline
\end{tabular}

تغييرهاى سهم نيروى كار و روند اين تغييرها با لحاظ نفت در محاسبهها در نمودارهاى ( (1) و (r)

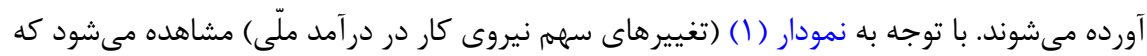

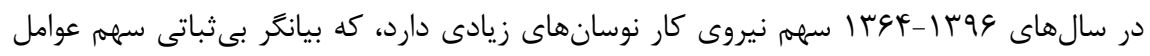

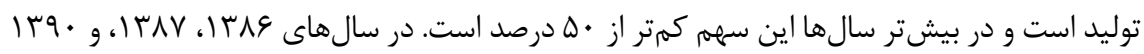

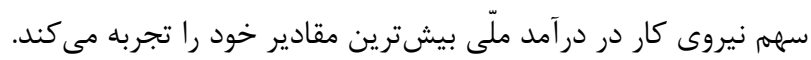




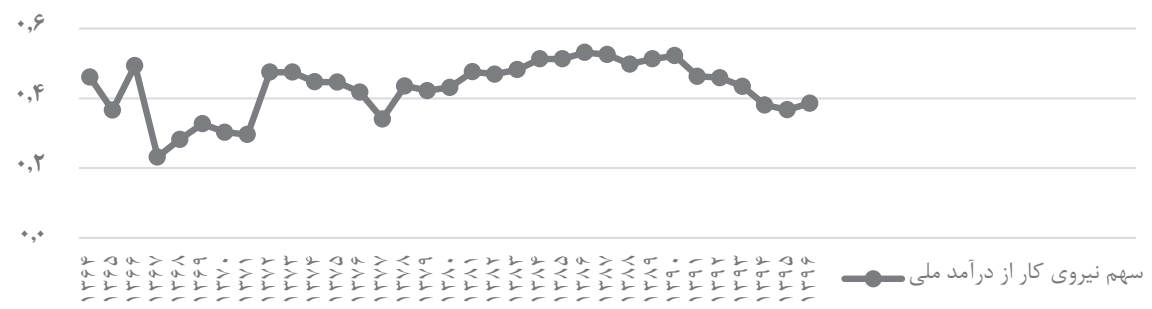

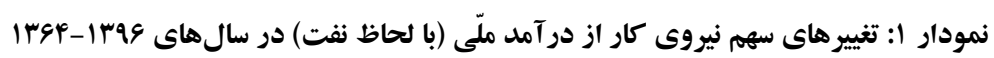

همانطور كه در نمودار (r) (روند سهم عامل كار از درآمد ملّى) مشاهده مىشود، در بازه

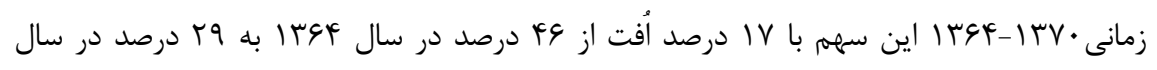

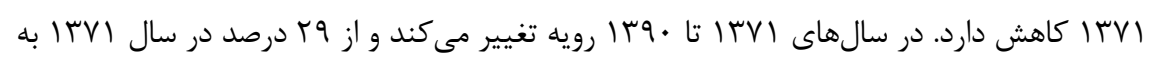

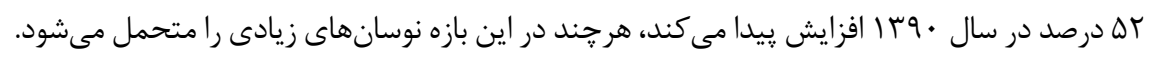

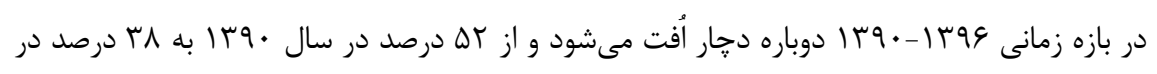

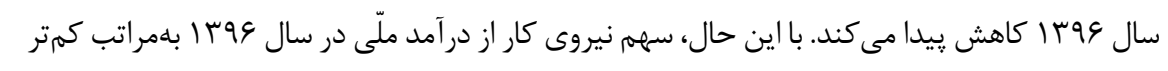
از مقدار آن در سالهاى قبل است و به نظر راه زيادى تا رسيدن مجدد به اين مقدار دارد.

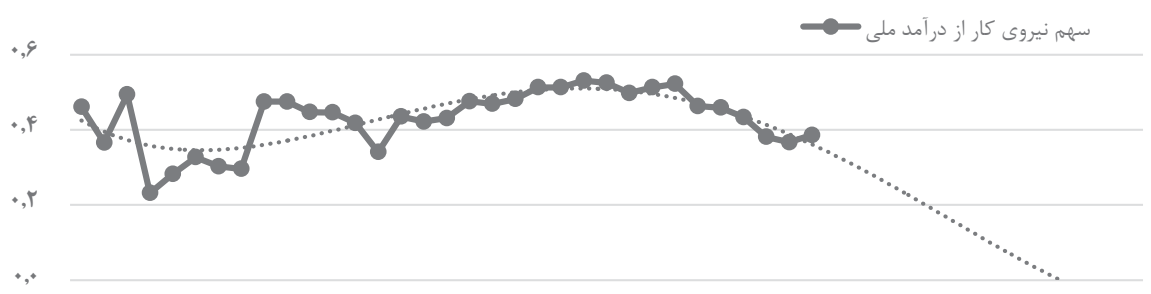
等

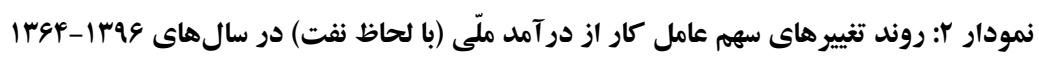

تغييرهاى سهمم سرمايه از درآمد ملّى كه در محاسبه آن از توليد ناخالص داخلى با لحاظ نفت

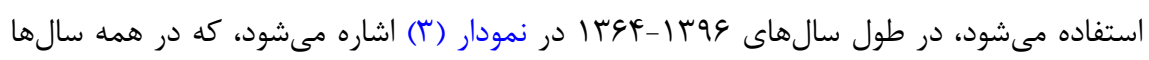




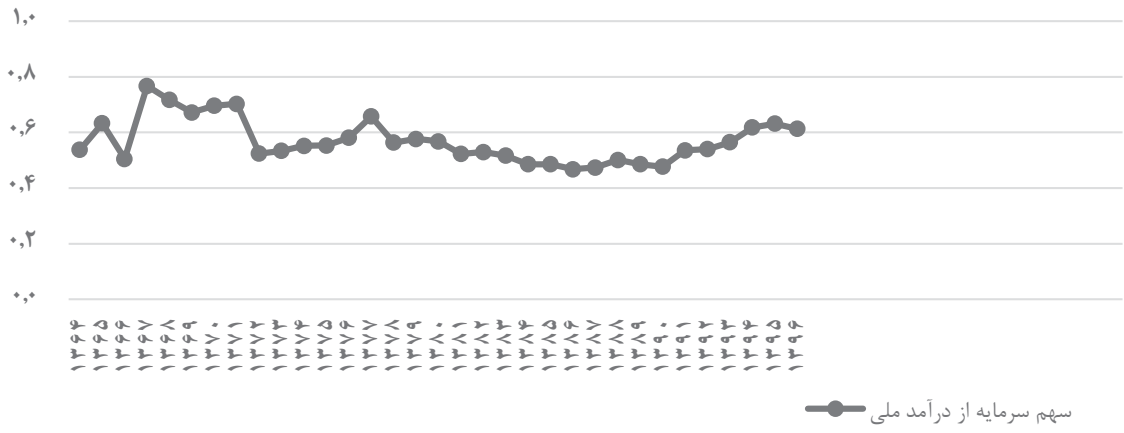

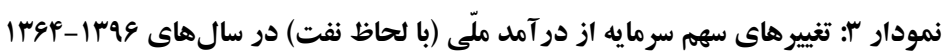

همجنين روند كلى سهم اين عامل از در آمد ملّى نمودار (Y)، روند فزايندهاى دارد و در ساليان اخير به بالاتر از • له درصد مىرسد، و همين امر نشاندهنده كاهش سهمبرى نيروى كار است.

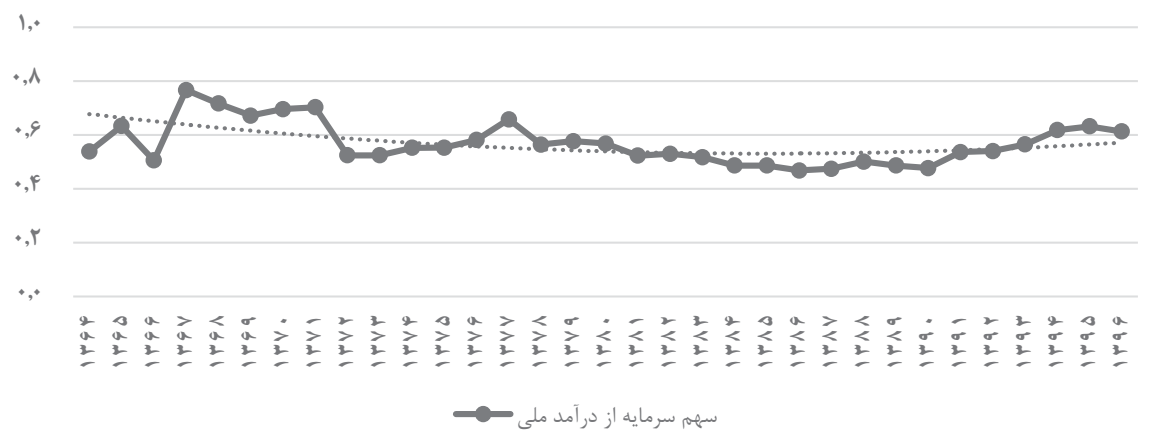

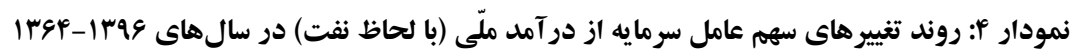

تغييرهاى سهم نيروى كار در درآمد ملّى با استفاده از توليد ناخالص داخلى بدون نفت حاكى از

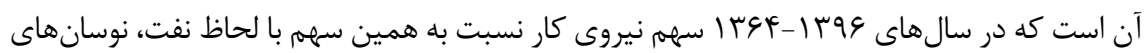

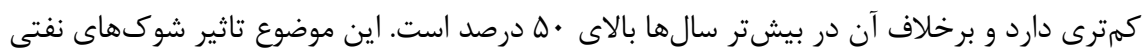

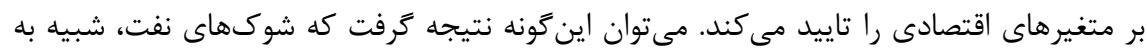
يك شوى منفى فناورى، باعث انقباض در فعاليتهاى اقتصادى از جمله در اين مورد باعث كاهش مون 


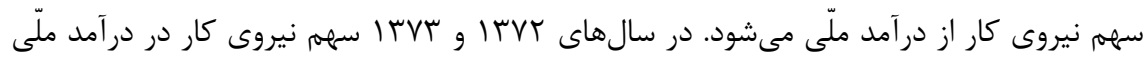

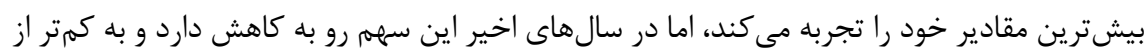

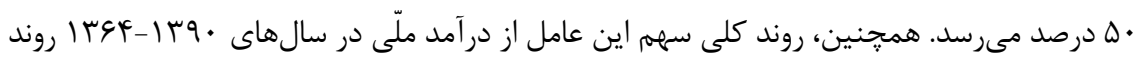

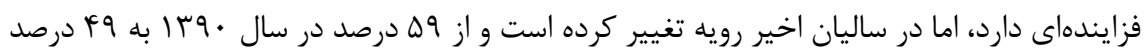

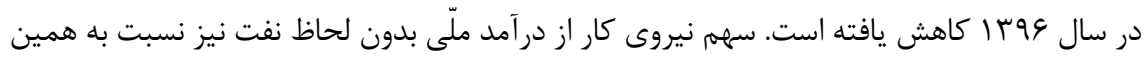

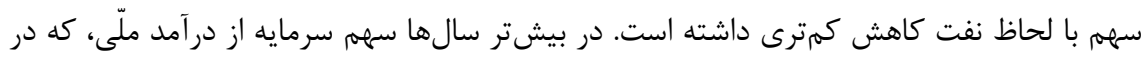

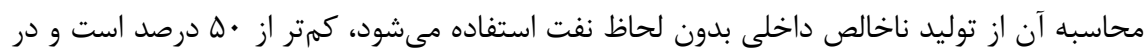

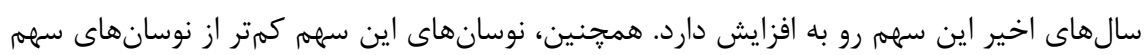

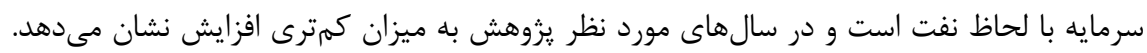

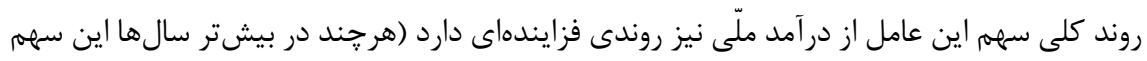

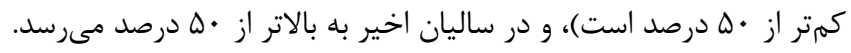

\section{عوامل موثر بر سهمبرى كار و سرمايه}

در يزروهش حاضر يّ از محاسبه سهم عوامل كار و سرمايه، مطابق با رويكرد يِيكتى (نخستين

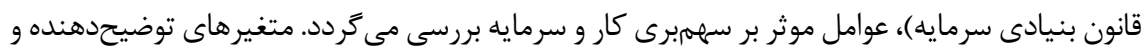

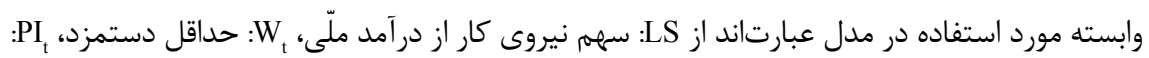

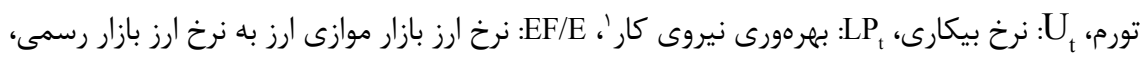

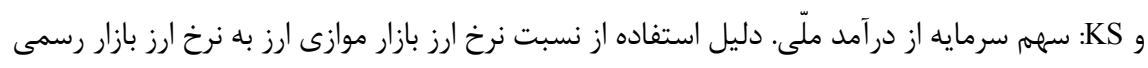

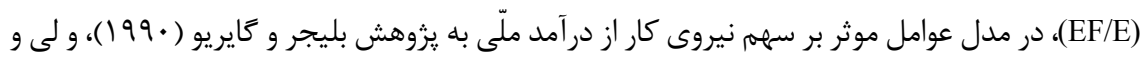

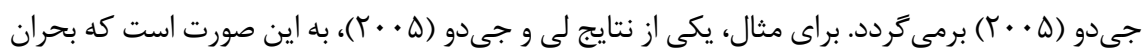

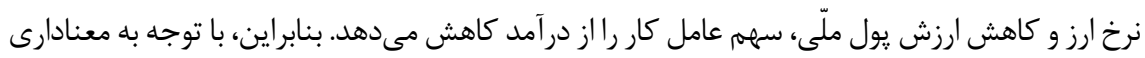

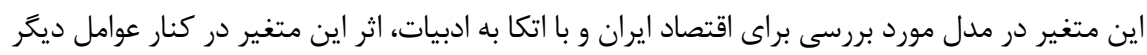

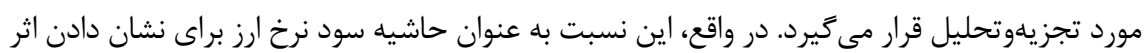

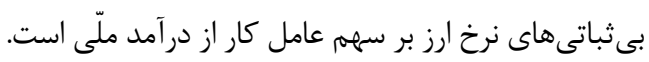




\section{بررسى يايايى متغيرها و تدوين مدل}

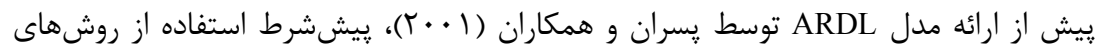

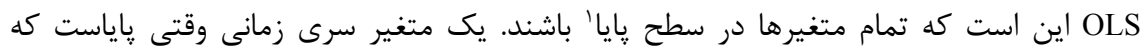

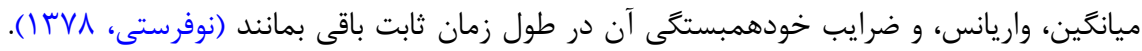
ولى بلندرت اين مورد بِيش مىآيد، بدينترتيب از روشهاى همجمعى استفاده مىشود. مزيت استفاده

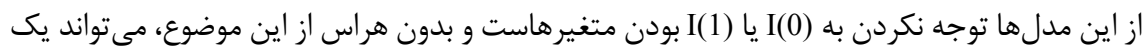

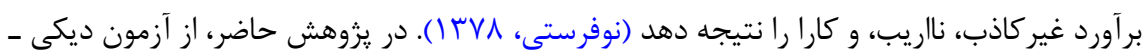
فولر تعميميافته براى تشخيص يايايى متغيرها استفاده مىشود. نتايج آزمون ديكى ـ فولر تعميميافته

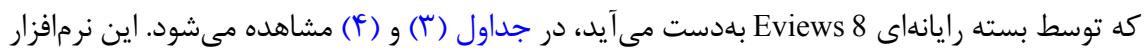

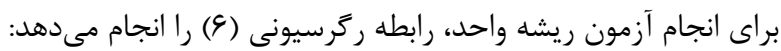
$\Delta \mathrm{Y}_{\mathrm{t}}=\alpha+\beta \mathrm{t}=\delta \mathrm{Y}_{\mathrm{t}-1}+\sum_{\mathrm{i}=1}^{\mathrm{p}} \theta_{\mathrm{i}} \Delta \mathrm{Y}_{\mathrm{t}-\mathrm{i}}+\varepsilon_{\mathrm{t}}$

$\mathrm{H}_{0}: \delta=0 \quad \mathrm{H}_{1}: \delta<0$

فرض صفر مبنى بر نايايا بودن و فرض يك مبنى بر پايايى سرى زمانى است.

جدول זّ: نتايج آزمون ديكى -فولر براى بررسى پايايى در سطح متغيرهاى مدل ARDL

\begin{tabular}{|c|c|c|c|c|}
\hline \multicolumn{3}{|c|}{$\begin{array}{c}\text { مقادير بحرانى مك كينان } \\
\text { MacKinon Critical Values }\end{array}$} & \multirow[t]{2}{*}{ آماره ADF } & \multirow{2}{*}{ متغير مورد نظر } \\
\hline$\%$ & $\% \Delta$ & $\%$ & & \\
\hline 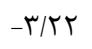 & $-r / \Delta V$ & $-\boldsymbol{F} / \boldsymbol{\mu}$. & $-r / 99$ & LSoil \\
\hline$-1 / 9$. & $-1 / 90$ & $-r / 99$ & $\cdot 179$ & LSfreeoil \\
\hline$-1 / 9$. & $-1 / 90$ & $-r / 99$ & $-1 / 91$ & $\mathrm{Wt}$ \\
\hline$-r / 9 Y$ & $-Y / 99$ & $-r / 9 V$ & $-r / 4 V$ & PIt \\
\hline$-|/ 9|$ & $-1 / 90$ & $-r / g F$ & - & $\mathrm{Ut}$ \\
\hline$-|/ 9|$ & $-1 / 90$ & $-r / 94$ & $1 / \cdot 9$ & LPt \\
\hline$-1 / 9$ & $-1 / 90$ & $-r / 9 \Delta$ & $r / \cdot \Delta$ & $\mathrm{EF}$ \\
\hline$-1 / 91$ & $-1 / 90$ & $-r / g F$ & r/Vr & $\mathrm{E}$ \\
\hline
\end{tabular}

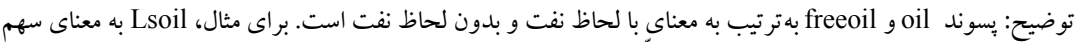

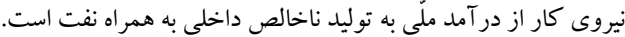


همانطور كه در جدول (r) مشاهده مىشود، از بين متغيرهاى سرى زمانى بهجز متغيرهاى

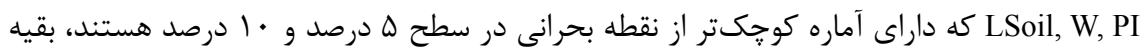

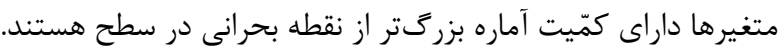

\begin{tabular}{|c|c|c|c|c|}
\hline \multicolumn{3}{|c|}{$\begin{array}{c}\text { مقادير بحرانى مك كينان } \\
\text { MacKinon Critical Values }\end{array}$} & \multirow{2}{*}{$\begin{array}{l}\text { ADF } \\
\text { ADار }\end{array}$} & \multirow{2}{*}{ متغير مورد نظر } \\
\hline$\% 1$. & $\% \Delta$ & $\%$ & & \\
\hline$-r / g r$ & $-r / 9 V$ & $-r / G \Lambda$ & $-\Delta / \Delta \omega$ & $\mathrm{U}_{\mathrm{t}}$ \\
\hline$-r / 9 T$ & $-r / 9 V$ & $-r / G \Lambda$ & $-F / 9 \varphi$ & $\mathrm{LP}_{\mathrm{t}}$ \\
\hline$-Y / G T$ & $-T / 9 V$ & $-r / \varepsilon \wedge$ & $-Y / 9 V$ & $\mathrm{EF}$ \\
\hline$-Y / G T$ & $-r / 9 V$ & $-r / 9 \wedge$ & $-r / \cdot \Delta$ & E \\
\hline$-Y / G T$ & $-T / 9 V$ & $-r / 9 \Lambda$ & $-N / \Delta r$ & LSfreeoil \\
\hline
\end{tabular}

همانطور كه در جدول (f) مشاهده مىشود، متغيرهاى مورد نظر همكى با يكبار تفاضل

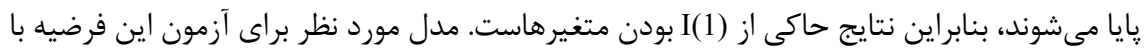

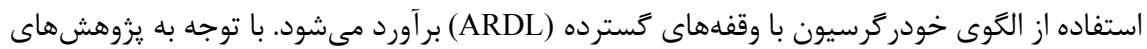
پيشين در بخش توزيع درآمد در سطح جهانى و در سطح داخلى، و همجنين با توجه به وضعيت

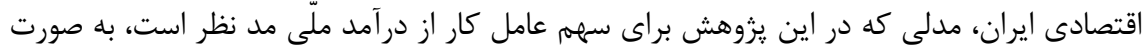
رابطه (V) تعريف مىشود: إنى مدى

$\mathrm{LS}=\mathrm{f}\left(\mathrm{W}_{\mathrm{t}}, \mathrm{PIt}, \mathrm{U}_{\mathrm{t}}, \mathrm{LP}_{\mathrm{t}},(\mathrm{EF} / \mathrm{E})_{\mathrm{t}}\right)$

در اين الكَ، علاوه بر روابط بلندمدت، الكوى تصحيح خطا' (ECM) كوتاهمدت نيز ارائه مىشود.

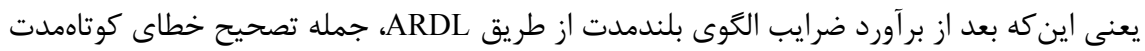
كه همان خطاى ركرسيون الكوى دستيابى بلندمدت است، با يك وقفه به عنوان يك متغير (ECT)

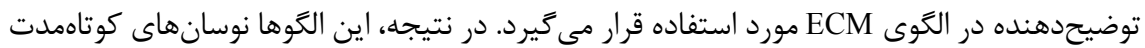

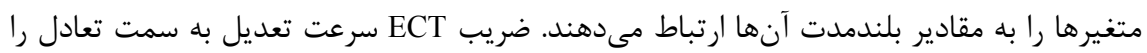
نشان مى دهد و انتظار مىرود از نظر علامت منفى باشد. مدل ARDL براى توابع سهمبرى عوامل كار 
$(L S) t=\sum_{j=1}^{p} \alpha_{j}(L S)_{t-j}+\sum_{j=0}^{q_{1}} \beta_{1 j}(W)_{t-j}+\sum_{j=0}^{q_{2}} \beta_{2 j}(P I)_{t-j}$

$+\sum_{j=0}^{q_{3}} \beta_{3 j}(U)_{t-j}+\sum_{j=0}^{q_{4}} \beta_{4 j}(L P)_{t-j}+\sum_{j=0}^{q_{5}} \beta_{5 j}\left(\frac{E F}{E}\right)_{t-j}+U_{t}$

پيش از بحث ييرامون روابط تعادلى بلندمدت، ضرورى است آزمون ريشه واحد فرضيه صفر، نبود

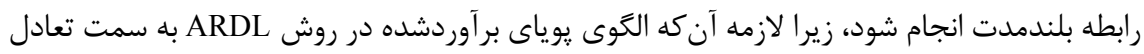

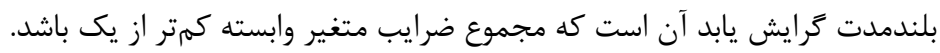
$\mathrm{H}_{0}: \sum_{\mathrm{j}=1}^{\mathrm{p}} \alpha_{\mathrm{j}}-1 \geq 0$

$\mathrm{H}_{1}: \sum_{\mathrm{j}=1}^{\mathrm{p}} \alpha_{\mathrm{j}}-1 \leq 0$

كمّيت آماره t مورد نياز براى انجام آزمون بالا به صورت رابطه ( • () محاسبه مىشود:

$\mathrm{t}=\frac{\sum_{\mathrm{j}=1}^{\mathrm{p}} \hat{\alpha} \mathrm{j}-1}{\sum_{\mathrm{j=1}}^{\mathrm{p}} \mathrm{S}_{\hat{\alpha} \mathrm{j}}}$

با مقايسه مقدار آماره t و كمّيت بحرانى ارائهشده توسط بنرجى و همكاران' (سو99()، در سطوح

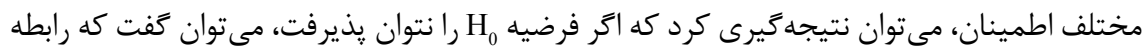

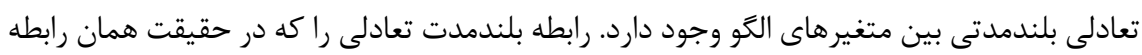

$(\mathrm{LS})_{\mathrm{t}}=\delta_{1}(\mathrm{~W})_{\mathrm{t}}+\delta_{2}(\mathrm{PI})_{\mathrm{t}}+\delta_{3}(\mathrm{U})_{\mathrm{t}}+\delta_{4} \mathrm{LP}_{\mathrm{t}}+\delta_{5}(\mathrm{EF} / \mathrm{E})_{\mathrm{t}}$ كه در آن ضرايب بلندمدت از طريق رابطه (T () محاسبه مى $\widehat{\delta}_{i}=\frac{\sum_{j=0}^{\widehat{\mathrm{q}}_{\mathrm{i}}} \widehat{\beta}_{\mathrm{ij}}}{1-\sum_{\mathrm{j}=1}^{\widehat{\mathrm{p}}} \widehat{\alpha}_{\mathrm{j}}} \mathrm{i}=1, \ldots, 6$

براى تنظيم الكَوى تصحيح خطا كافى است كه جملههاى خطاى مربوط به ركرسيون همگرايى 
در بلندمدت را با يك وقفه زمانى به عنوان متغيرى توضيحدهنده در كنار تفاضل مرتبه اول ديگر

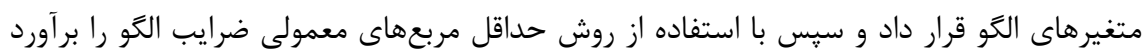

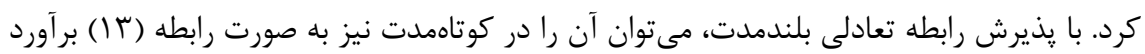
كرد و مورد بررسى قرار داد: $\Delta(\mathrm{LS})_{\mathrm{t}}=\theta_{0}+\theta_{1} \Delta(\mathrm{W})_{\mathrm{t}}+\theta_{2} \Delta(\mathrm{PI})_{\mathrm{t}}+\theta_{3} \Delta(\mathrm{U})_{\mathrm{t}}+\theta_{4} \Delta(\mathrm{LP})_{\mathrm{t}}+\theta_{5} \Delta(\mathrm{EF} / \mathrm{E})_{\mathrm{t}}+\theta_{6} \hat{\varepsilon}_{\mathrm{t}-1}+\Sigma_{\mathrm{t}}$

ييش از ارائه نتايج برآورد الكو، يافتههاى برآورد تابع كاب داگلاس بلطور مختصر در جدول (ه)

\begin{tabular}{|c|c|c|c|}
\hline \multicolumn{4}{|c|}{ جدول ه: نتايج بر آورد تابع كاب داكلاس } \\
\hline آماره & انحراف معيار & ضرايب & متغيرها \\
\hline$F / v$ & $.1 \cdot 9$ & $\cdot / F F$ & LK \\
\hline$V / 9 \Lambda$ & .111 & $\cdot 119$ & LL \\
\hline$-1 \cdot / 4 F$ & $\cdot / V r$ & $-V / V T$ & $\mathrm{C}$ \\
\hline$r / \cdot 1$ & $\cdot / \cdot r$ & $\cdot / \cdot V$ & D8990 \\
\hline
\end{tabular}

$\mathrm{R}^{2}=0.98$

همانطور كه نتايج جدول (ه) نشان مىدهد كشش سرمايه به توليد برابر با fF/• است.

\section{نتايج بر آورد الكو و تفسير نتايج}

در ادامه، نتايج مدل مورد نظر براى بررسى عوامل موثر بر سهمم نيروى كار از درآمد ملّى با لحاظ

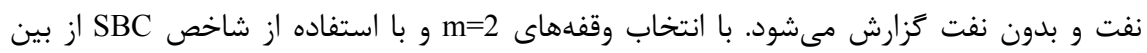
ARDL $(1,2,2,1,2,0)$ معادله برآوردشوان بهترين معادله عوامل موثر بر سهمبرى نيروى كار با لحاظ نفت انتخاب مىشود كه نتايج اوليه آن در جدول (9) ارائه مىشود. 


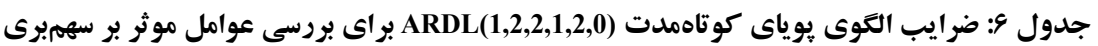
نيروى كار با لحاظ نفت

\begin{tabular}{|c|c|c|c|}
\hline آماره & انحراف معيار & ضرايب & متغير ها \\
\hline$-N / G \Delta T$ & $\cdot 11 \cdot f$ & -.19 .9 & L(LSoil(-1)) \\
\hline I/ETV & $\cdot / T V$. & . / К & $\mathrm{L}(\mathrm{W})$ \\
\hline - F/Tar & $\cdot|f| f$ & $-1 / \Lambda \cdot \Delta$ & $\mathrm{L}(\mathrm{W}(-1))$ \\
\hline N/VVT & $\cdot / T F$. & $r / l \cdot \Lambda$ & $\mathrm{L}(\mathrm{W}(-2))$ \\
\hline$-r / T V V$ & $\cdot \mid \cdot \Delta 1$ &.$- / 191$ & $\mathrm{~L}(\mathrm{PI})$ \\
\hline$-r / \Lambda \cdot F$ & $\cdot 1 \cdot v \cdot$ & $-\cdot / 19 \mathrm{~V}$ & $\mathrm{~L}(\mathrm{PI}(-1))$ \\
\hline -T/KIT & $\cdot / \cdot r \Lambda$ & $-\cdot 1 \cdot 19$ & $\mathrm{~L}(\mathrm{PI}(-2))$ \\
\hline$-r / 1 \wedge 9$ & . ITFT & س & $\mathrm{L}(\mathrm{U})$ \\
\hline$-Q / \cdot \lambda r$ & $\cdot / r \cdot f$ & $-1 / \cdot f \cdot$ & $\mathrm{L}(\mathrm{U}(-1))$ \\
\hline - & $\cdot / 4 q \Delta$ & $-1 / 1 \wedge \Delta$ & L(LP) \\
\hline$r / \Lambda \cdot r$ & $\cdot|\Delta V|$ & T/VAT & $\mathrm{L}(\mathrm{LP}(-1))$ \\
\hline$r / \Delta V F$ & •/rAV & .1991 & $\mathrm{~L}(\mathrm{LP}(-2))$ \\
\hline$-Y / V \& 9$ & $\cdot 1 \cdot T V$ & $-\cdot 1 \cdot \sqrt{ } 9$ & $\mathrm{~L}(\mathrm{EF} / \mathrm{E})$ \\
\hline$r / 9 r \wedge$ & $.1 .9 \Lambda$ & צמr/. & D7982 \\
\hline $9 / 499$ & .1 .4$. & $\cdot / r \wedge \Delta$ & D7375 \\
\hline$-r / 99$. & $\cdot \mid \cdot V_{1}$ & $-\cdot / 119$ & D88 \\
\hline$-\Delta / \Delta \vee \Delta$ & $T / T / S$ & $-\mid r / T \Delta F$ & $\mathrm{C}$ \\
\hline$-8|\lambda \Delta|$ &.$/ \cdot T F$ & $-\cdot / 19 \wedge$ & TREND \\
\hline
\end{tabular}

$\mathrm{DW}=\mathrm{T} / \mathrm{FF} \quad \mathrm{R}^{2}=\cdot / 91$

با توجه به خروجى برآورد، مىتوان كفت در اين الكو تمامى ضرايب اين متغيرها يا وقفههاى

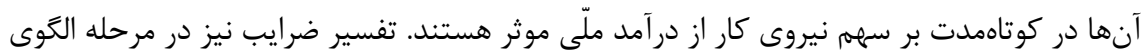

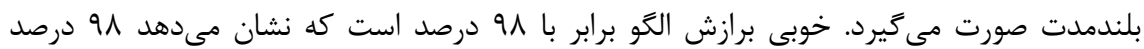

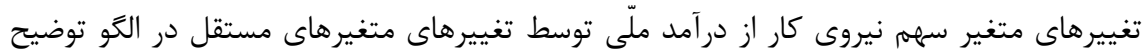

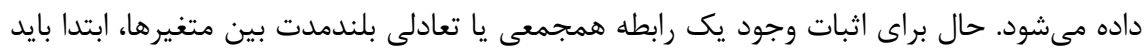
آزمون بنرجى و همكاران (ب99 () انجام شود. با توجه به مجموع ضرايب وقفه ادهاى متغير وابسته و نيز 


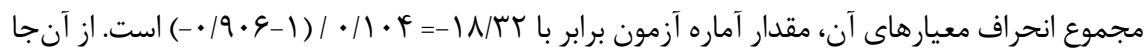

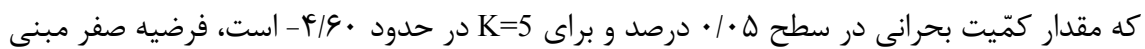

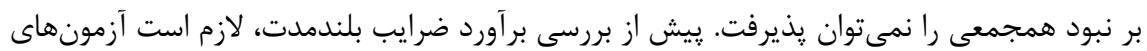

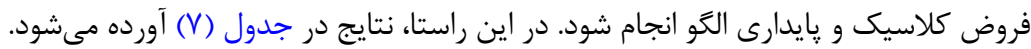

جدول Y: آزمونهاى فروض كلاسيك براى جملههاى خطاى بر آورد مدل يوياى كوتاهمدت

\begin{tabular}{|c|c|c|c|}
\hline نتيجه & سطح احتمال & كمّيتهاى آمارى & فرضيه صفر \\
\hline رد نشدن H & $\cdot|\wedge|$ & $\mathrm{J}-\mathrm{B}=\cdot / \mathrm{q \Lambda}$ & توزيع نرمال \\
\hline رد نشدن ر &.$/ 11$ & $F=r / l r$ & نبود خودهمبستخى \\
\hline رد نشدن ر & $.19 V$ & $\mathrm{~F}=\cdot / \mathrm{r} \Delta$ & همسانى واريانس \\
\hline رد نشدن H & .194 & $\mathrm{~F}=\cdot|T Y|$ & تصريح مناسب \\
\hline
\end{tabular}

همانطور كه در جدول (V) مشاهده مىشود، نتايج آزمون فروض كلاسيك حاكى از نبود خودهمبستخى، ناهمسانى واريانس، و توزيع نرمال جملههاى خطاست. تصريح مناسب الخو از طريق

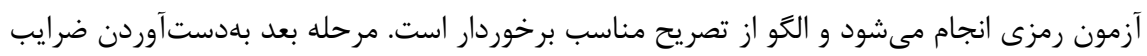

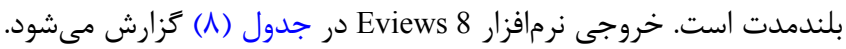

جدول ^: بر آورد ضرايب بلندمدت الكو براى بررسى عوامل موثر بر سهمبرى نيروى كار با لحاظ نفت

\begin{tabular}{|c|c|c|c|}
\hline آماره & انحراف معيار & ضرايب & متغيرها \\
\hline 9/919 & $\cdot / \cdot \Delta F$ & $\cdot|r \varphi|$ & $\mathrm{L}(\mathrm{W})$ \\
\hline$-\Delta / V Y q$ & $\cdot|\cdot|+\mid$ & - & L(PI) \\
\hline -r/A9T &.$/ 19 \wedge$ & $-\cdot / A T \Delta$ & $\mathrm{L}(\mathrm{U})$ \\
\hline 9/99 & .1191 & $1 / K r$. & L(LP) \\
\hline - T/VTY & $.1 .1 \mathrm{~F}$ & $-\cdot \cdot \cdot r$. & $\mathrm{L}(\mathrm{EF} / \mathrm{E})$ \\
\hline ब/र१९ & תr.|• & $\cdot / 1 V 9$ & D7982 \\
\hline 9/9rr & $\cdot 1 \cdot r q$ & $\cdot / r \cdot r$ & D7375 \\
\hline- T/GYQ & $\cdot 1 \cdot r V$ & -.1 .99 & D88 \\
\hline$-\Delta / 4 q \varphi$ & $1 / 1 \vee q$ & $-\varepsilon / 4 \lambda$. & $\mathrm{C}$ \\
\hline$-9 / 91$. & $\cdot / \cdot I r$ & $-\cdot / \cdot \wedge \Lambda$ & TREND \\
\hline
\end{tabular}




\section{نتايج بر آورد ضرايب بلندمدت الكو}

يِيش از ارائه نتايج برآورد ضرايب بلندمدت الكَ بيان اين نكته داراى اهميت است كه جون جمع

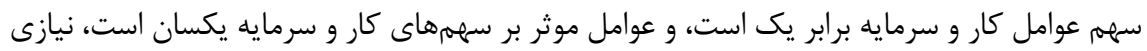
به برآورد معادله مجزا براى سهمم عامل سرمايه نيست و فقط علامتهاى ضرايب متفاوت هستند. با يا توجه به خروجى برآورد مىتوان كَفت تمامى متغيرهاى مورد استفاده در مدل معنادار هستند، يعنى

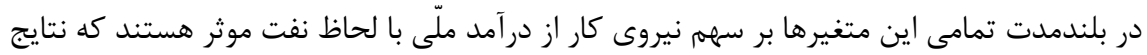
به اين شرح است: در اين مدل با افزايش يك درصد در سطح حداقل دستمزد، سهمم نيروى كار از

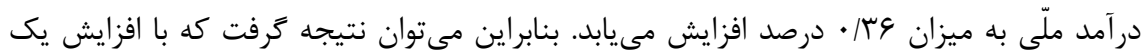

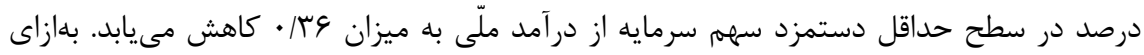

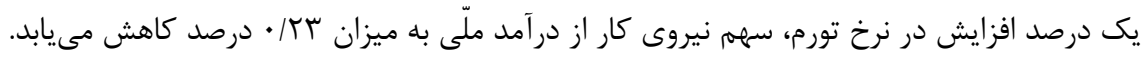

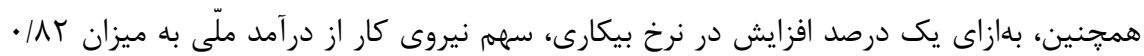

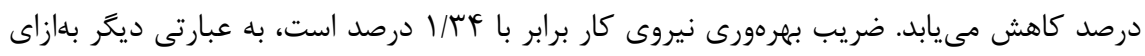

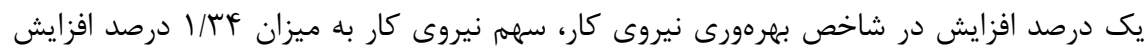

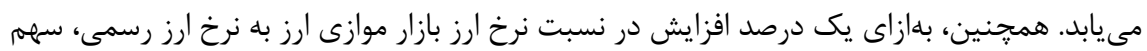

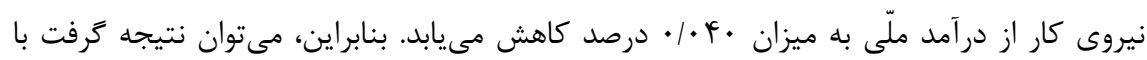

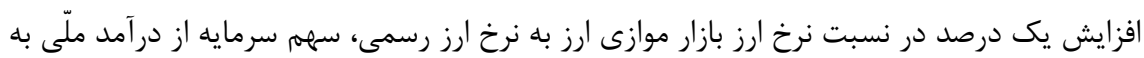

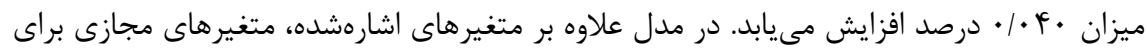

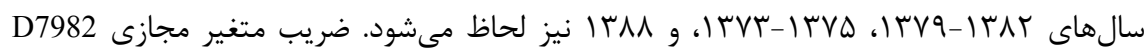

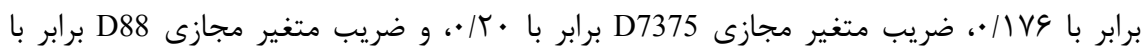

\section{بر آورد الكوى تصحيح خطا}

يس از اثبات وجود رابطه همجمعى بين متغيرهاى الكو كه نتايج آن در جدول ( () آورده مىشود،

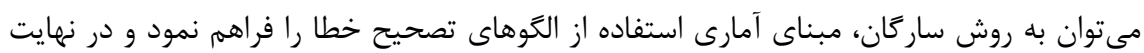
نوسانهاى كوتاهمدت متغيرها را به مقادير بلندمدت آنها مربوط ساخت. در جدول (9)، ضرايب الكوى تصحيح خطا آورده مىشود. 
جدول و: ضرايب الكوى تصحيح خطا براى بررسى عوامل موثر بر سهمبرى نيروى كار با لحاظ نفت

\begin{tabular}{|c|c|c|c|}
\hline آماره & انحراف معيار & ضرايب & متغير ها \\
\hline I/ETV & $\cdot / T V$. & $\cdot / \pi \wedge \varepsilon$ & $\Delta \mathrm{L}(\mathrm{W})$ \\
\hline$-\Lambda / V V T$ & . ITF. & $-T / 1 \cdot \Lambda$ & $\Delta \mathrm{L}(\mathrm{W}(-1))$ \\
\hline$-r / T V V$ & $\cdot \mid \cdot \Delta 1$ & $-\cdot / 19 \wedge$ & $\Delta \mathrm{L}(\mathrm{PI})$ \\
\hline T/TIT &.$/ \cdot r \Lambda$ & $\cdot 1 \cdot 19$ & $\Delta \mathrm{L}(\mathrm{PI}(-1))$ \\
\hline$-r / / \wedge 9$ & . MFT & r. & $\Delta \mathrm{L}(\mathrm{U})$ \\
\hline$-r /$ TqT &.$/ 490$ & $-1 / 1 \wedge \Delta$ & $\Delta \mathrm{L}(\mathrm{LP})$ \\
\hline$-Y / \Delta V F$ & $\cdot / r A V$ &.$- / 991$ & $\Delta \mathrm{L}(\mathrm{LP}(-1))$ \\
\hline$-r / V \& 9$ &.$/ \cdot \mathrm{TV}$ & $-\cdot / \cdot v \varepsilon$ & $\Delta \mathrm{L}(\mathrm{EF} / \mathrm{E})$ \\
\hline F/9rA & .1 .91 & • & $\mathrm{D}(\mathrm{D} 7982)$ \\
\hline $9 / 499$ & .1 .4$. & $\cdot / \pi \wedge \Delta$ & $\mathrm{D}(\mathrm{D} 7375)$ \\
\hline$-r / 94$. & $\cdot 1 \cdot v 1$ & $-\cdot / 1199$ & $\mathrm{D}(\mathrm{D} 88)$ \\
\hline$-9|\wedge \Delta|$ &.$/ \cdot T F$ & $-\cdot / 19 \wedge$ & $\mathrm{D}$ (TREND) \\
\hline$-11 / 199$ & $\cdot 11 \cdot 4$ & $-1 / 9 \cdot 9$ & $\varepsilon^{\wedge} t-1$ \\
\hline
\end{tabular}

بر اساس نتايج جدول (9)، تمامى ضرايب متغيرها يا وقفههاى آنها معنادار هستند، اما جيزى كه در برآورد اخير داراى اهميت است، ضريب وقفه اول خطاى نبود تعادل است. در الكوهاى تصحيح خطا به منظور קايدارى الكو، ضريب ecm يا همان ضريب وقفه اول خطاى نبود تعادل بايد بين • و r- باشد. اگر

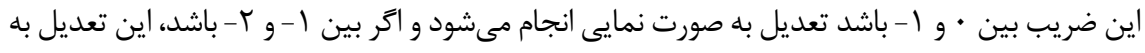

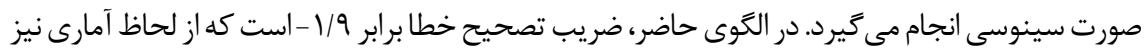
معنادار است. با توجه به مقدار ضريب برآوردشده، مىتوان كفت تعديل به سمت مقدار تعادلى و بلندمدت

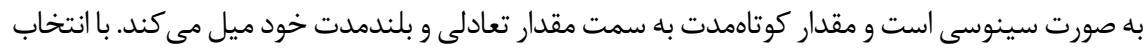

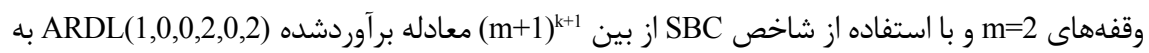
عنوان بهترين معادله عوامل موثر بر سهمبرى نيروى كار بدون لحاظ نفت انتخاب مىشود. خروجى برآورد

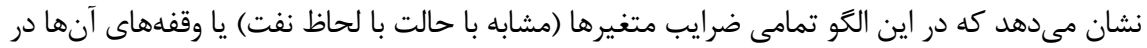

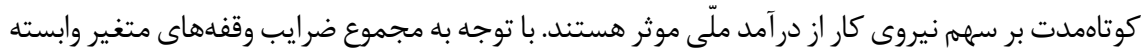

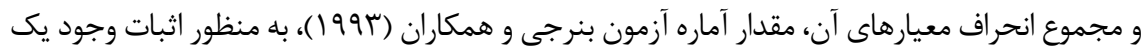




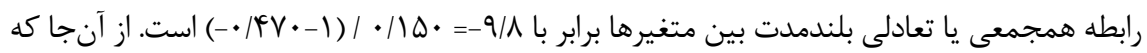

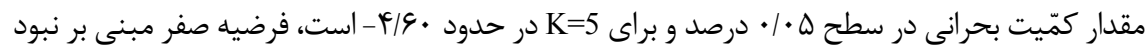
همجمعى را نمى توان يذيرفت. نتايج آزمون فروض كلاسيك نيز، حاكى از نبود خودهمبستكى، ناهمسانى

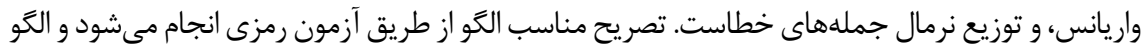
از تصريح مناسب برخوردار است. همجنين، خروجى برآورد حاكى از آن است كه تمامى متغيرهاى مورد

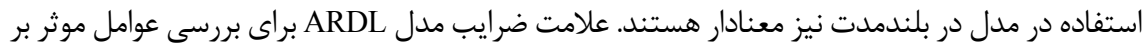
سهمبرى نيروى كار بدون لحاظ نفت بهجز ضريب نرخ بيكارى، مشابه با مدل قبل (با لحاظ نفت) است. با بـ

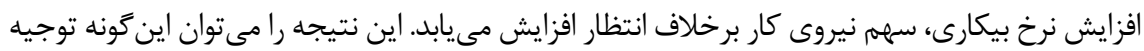

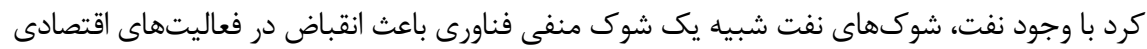

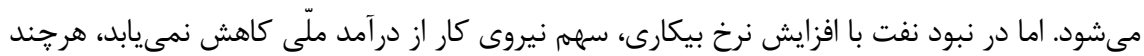

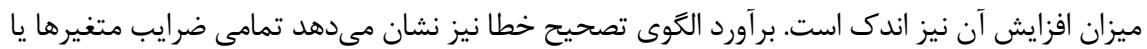
وقفههاى آنها معنادار هستند، اما جيزى كه در برآورد اخير داراى اهميت است، ضريب وقفه اول خطاى

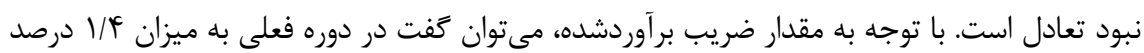
خطاى نبود تعادل دوره پِيشين تعديل مى گردد.

\section{بحث و نتيجهَ}

در اين يزوهش به محاسبه سهم هر يك از عوامل توليد كار و سرمايه در راستاى رويكرد يِيكتى

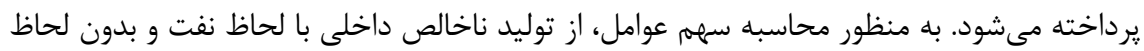
نفت استفاده مىشود. در جهت تحقق اين هدف، عوامل موثر بر سهمبرى نيروى كار و سرمايه از

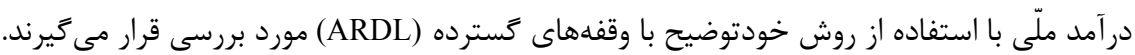

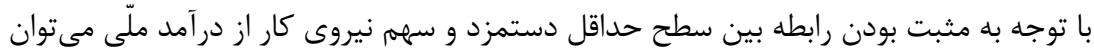

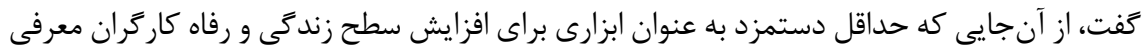
مىشود، مطابق با نظريه دستمزد كارايى منطقى است كه افزايش حداقل دستمزد موجب افزايش

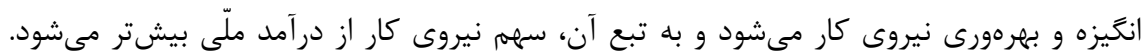

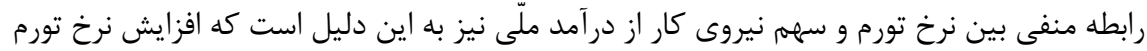

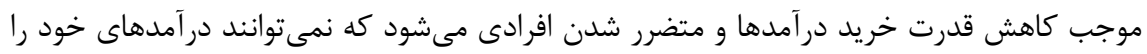

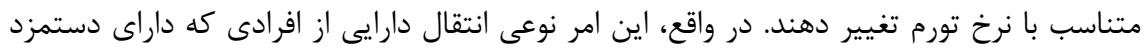


ثابتى هستند، به افرادى كه داراى سرمايه فيزيكى هستند، بهشمار مىرود. در نتيجه، تورم مىتواند به

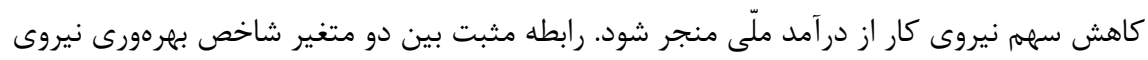

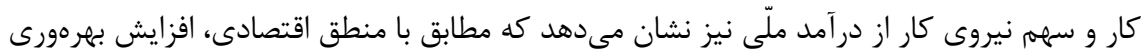
كار از طريق افزايش دستمزد به افزايش سهمم عامل كار منجر مىشود. همجنين، ارتباط منفى بين

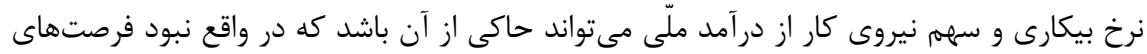

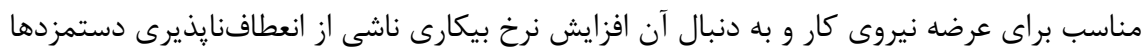
و ركود فعاليتهاى اقتصادى، مىتواند تاثير بسزايى در كاهش سهرم نيروى كار داشته باشد.

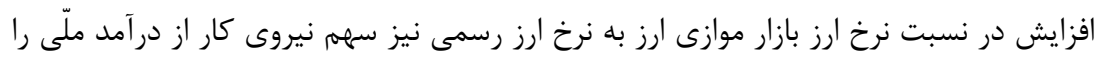

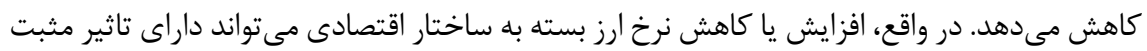

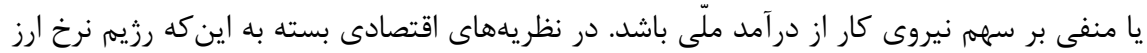

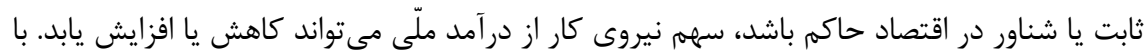

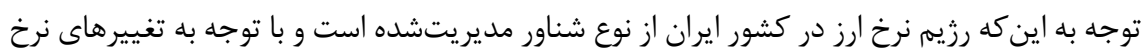

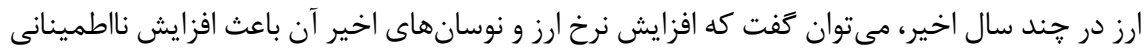
و ريسك مىشود و در نتيجه، ضدسرمايهگذارى و توليد عمل مى كند و با افزايش انتظارهاى تورمى لورى

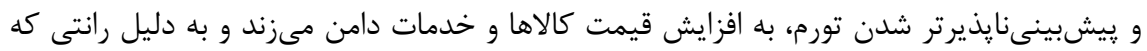

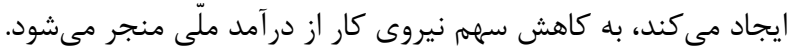

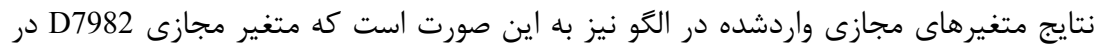
ارتباط با بهبود قيمت نفت در اواخر سال IrVA و بالا رفتن شاخصهاى بهرهورى به دليل تاكيد بر

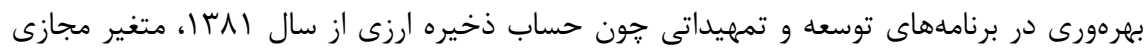

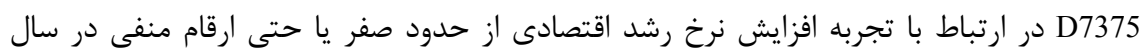

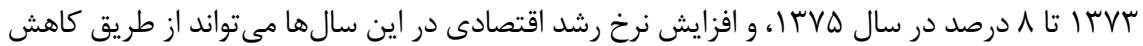

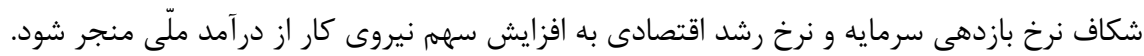

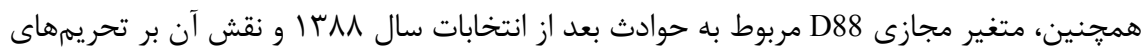

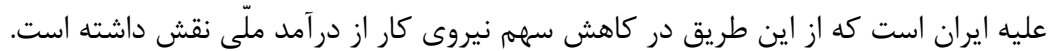
ضمن توجه به نتايج يزوهش، و روند كاهشى سهمم نيروى كار و روند افزايشى سهمم عامل سرمايه از

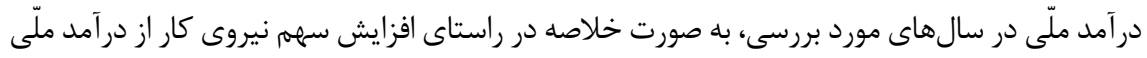

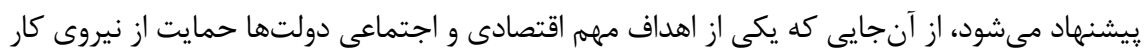


براى حفظ و ارتقاى قدرت خريد و تامين امنيت شغلى آنان با تعيين حداقل دستمزد مناسب است، پس كا تعيين حداقل دستمزد نيروى كار در سطحى كه علاوه بر تامين حداقل معيشت نيروى كار، تورم تاثير

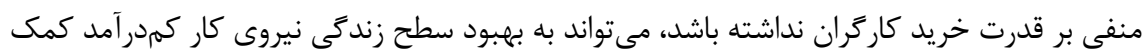

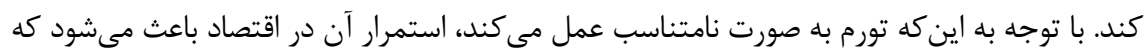
عوامل نامولد بدون ايجاد ارزش حقيقى درآمدهاى بالا كسب كنند كه اين درآمدها از سهمم عوامل توليد حقيقى برداشت مىشود. بنابر اين، سهمم دستمزدبخيران و نيروى كار بخش مولد بهشدت كاهش مى يابد.

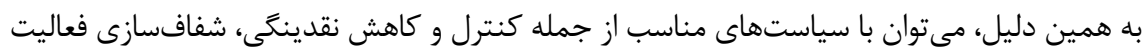

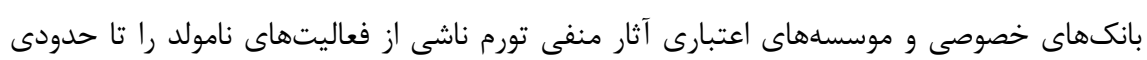
كاهش داد و از اين طريق موجب افزايش سهمه نيروى كار از درآمد ملّى شد.

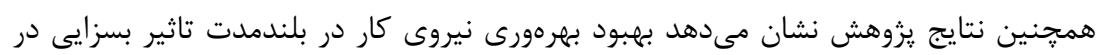

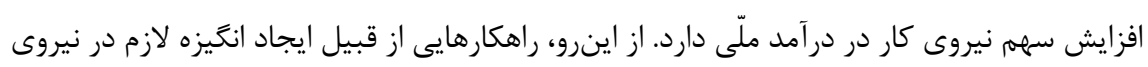

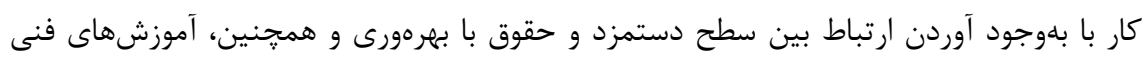

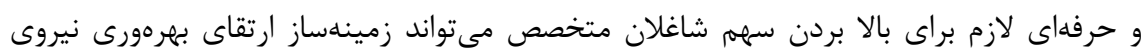

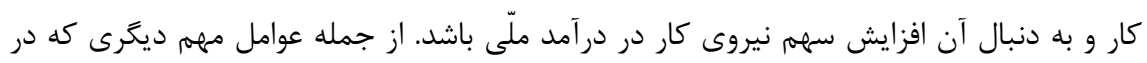

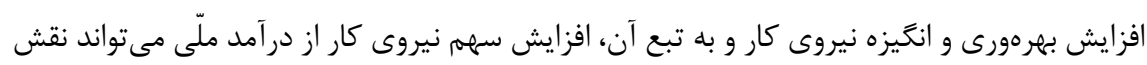

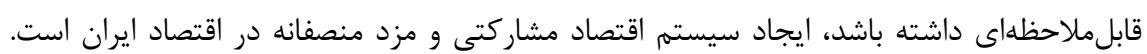

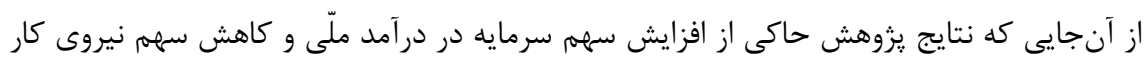

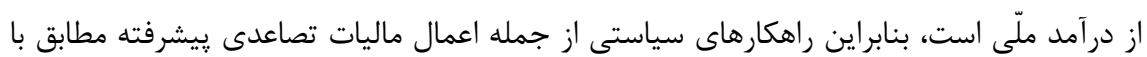

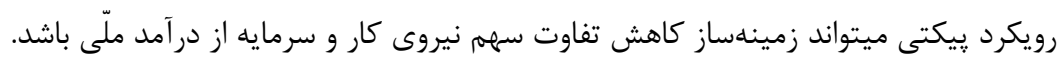

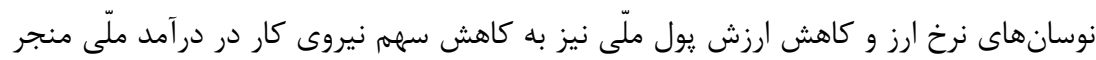

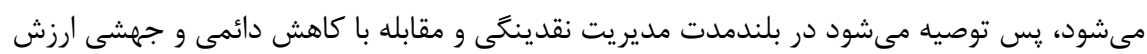

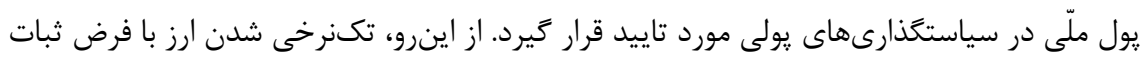

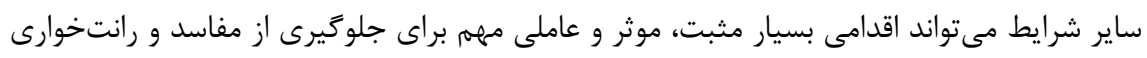

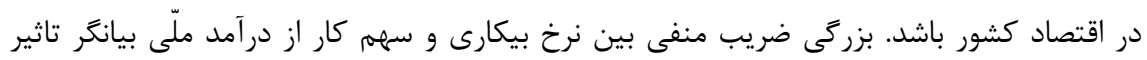

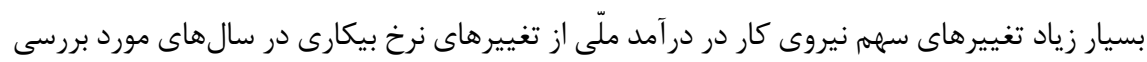

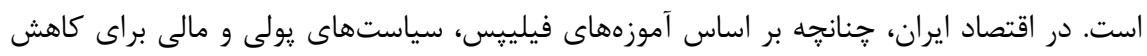
نرخ بيكارى بكار گرفته شود، ممكن است اشتغال در كوتاهمدت افزايش يابد، اما مى بوتواند به به بهاى 
افزايش تورم تمام شود. اما در بلندمدت با تعديل كامل انتظارها (با توجه به الكَوى انتظارهاى تطبيقى

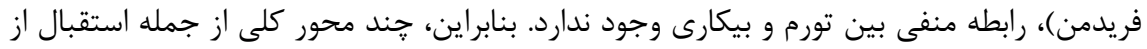

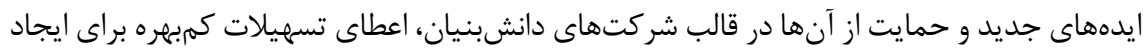

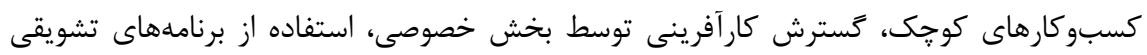

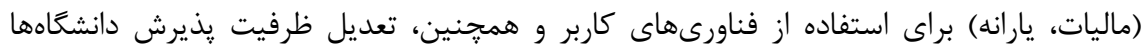

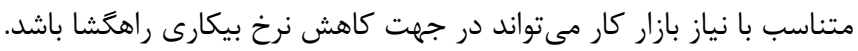

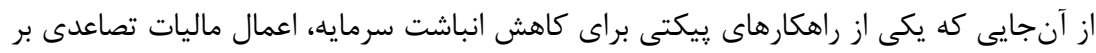

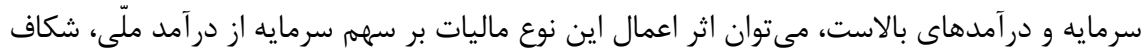

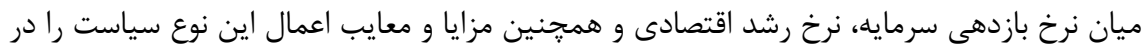

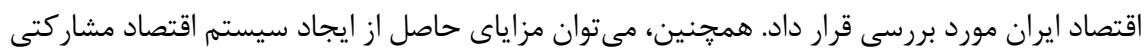

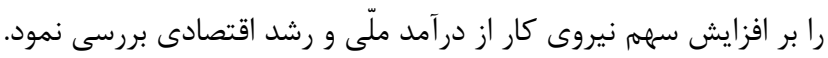

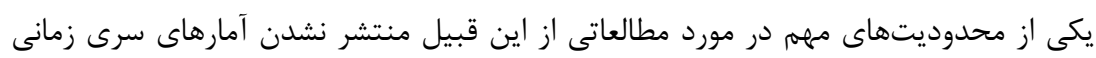

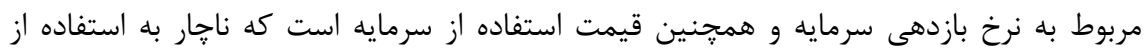

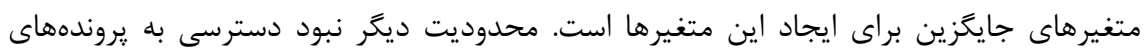

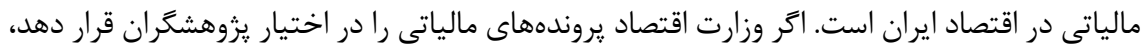

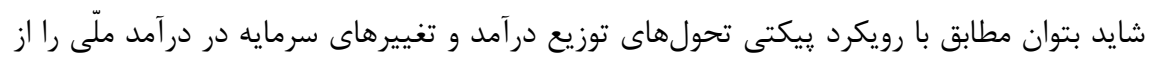
جايى كه سابقه مالياتى موجود است، بررسى كرد.

\section{منابع}

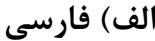

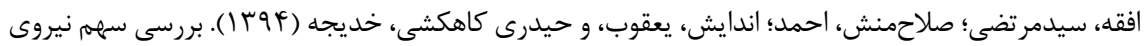

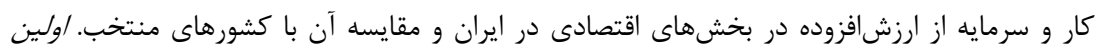

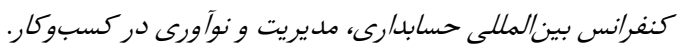

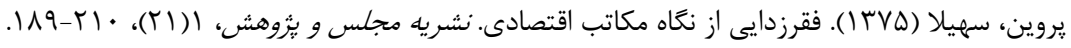

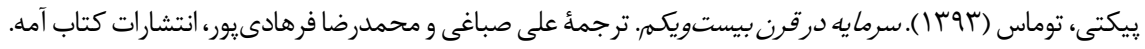




$$
\begin{aligned}
& \text { دادَر، يدالله؛ توتونجيان، ايرج، و آرمانمهر، محمدرضا (بوجا). تعادل بازار كار در الكوى شراكت كاركران در }
\end{aligned}
$$

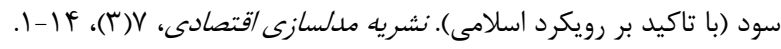

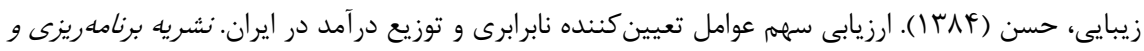

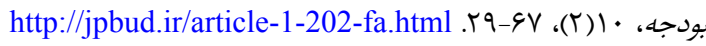

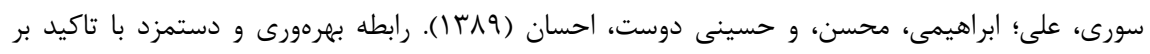

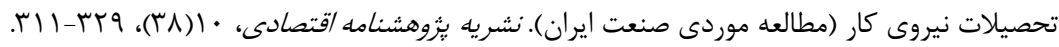

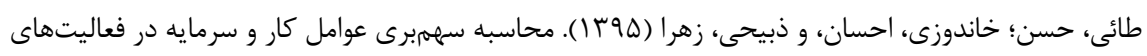

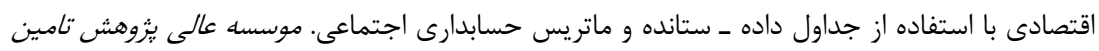

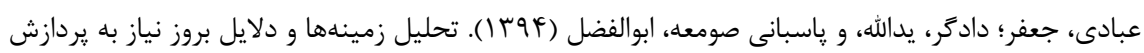

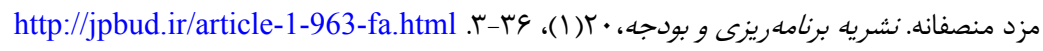

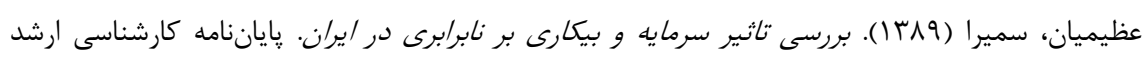

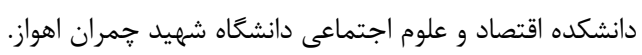

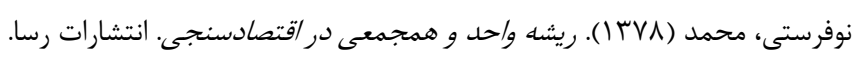

Banerjee, A., Dolado Lobregad, J. J., \& Mestre Zamarreño, R. (1993). On Some Simple Tests for Cointegration: The Cost of Simplicity: Banco de España. Servicio de Estudios.

Bengtsson, E. (2012). Labor's Share in Sweden, 18502000-. Institutionen för ekonomisk historia, 1-33.

Blejer, M. I., \& Guerrero, I. (1990). The Impact of Macroeconomic Policies on Income Distribution: An Empirical Study of the Philippines. The Review of Economics and Statistics, 72(3), 414423-. https://doi.org/10.2307/2109349.

Estrada, Á., \& Valdeolivas, E. (2014). The Fall of the Labor Income Share in Advanced Economies. Ensayos Económicos, 1(70), 47-81.

Guerriero, M., \& Sen, K. (2012). What Determines the Share of Labour in National Income? A Cross-Country Analysis. IZA Discussion Papers, No. 6643

Lee, K.-k., \& Jayadev, A. (2005). Capital Account Liberalization, Growth and the Labor Share of Income: Reviewing and Extending the Cross-Country Evidence. Capital Flight and Capital Controls in Developing Countries. Cheltenham: Edward Elgar, 15-57.

Pesaran, M. H., Shin, Y., \& Smith, R. J. (2001). Bounds Testing Approaches to the Analysis of Level Relationships. Journal of Applied Econometrics, 16(3), 289-326. https://doi.org/10.1002/jae.616.

Rodriguez, F., \& Jayadev, A. (2010). The Declining Labor Share of Income. Journal of Globalization and Development, 3(2), 1-18. 